\title{
Improving Ventilation and Saving Energy: Laboratory Study in a Modular Classroom Test Bed
}

\author{
Michael G. Apte, Ian S. Buchanan, David Faulkner, William J. Fisk, \\ Chi-Ming Lai ${ }^{*}$, Michael Spears, and Douglas P. Sullivan
}

\section{August 272005}

Indoor Environment Department

Environmental Energy Technologies Division

Lawrence Berkeley National Laboratory

*Department of Construction Technology

Leader University

Tainan City

Taiwan

This research was sponsored by the California Energy Commission through the Public Interest Energy Research program as the Lawrence Berkeley National Laboratory Classroom HVAC: Improving Ventilation and Saving Energy research project, CEC Contract Number 500-03-041. The study was additionally supported by the Assistant Secretary for Energy Efficiency and Renewable Energy, Building Technology Program of the U.S. Department of Energy under contract DE-AC02-05CH11231. 


\section{Table of Contents}

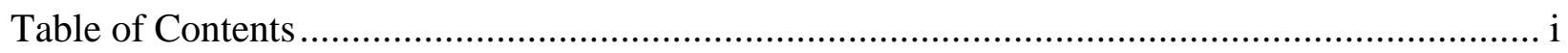

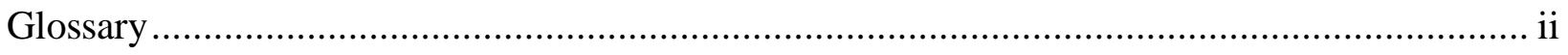

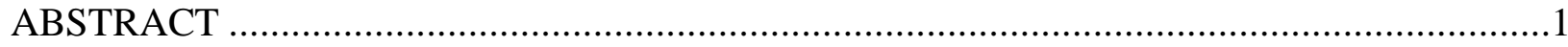

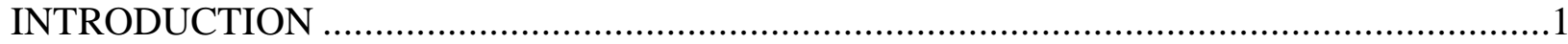

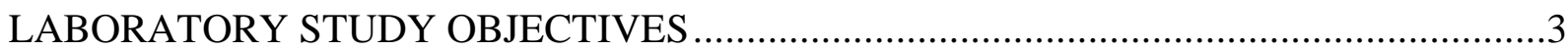

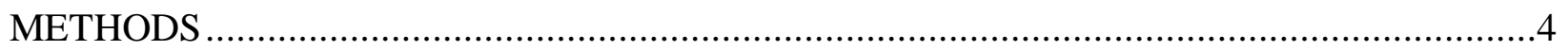

HVAC systems and controls, installation, and commissioning ............................................

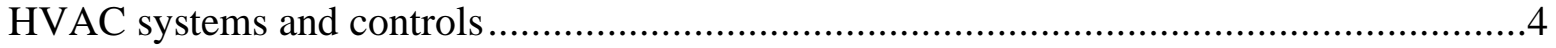

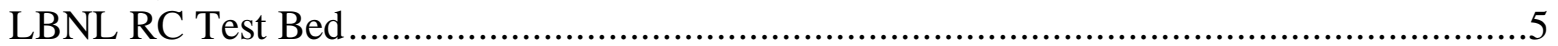

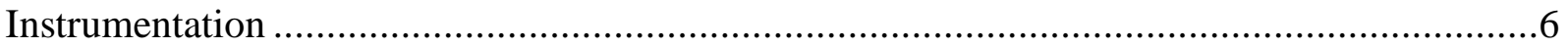

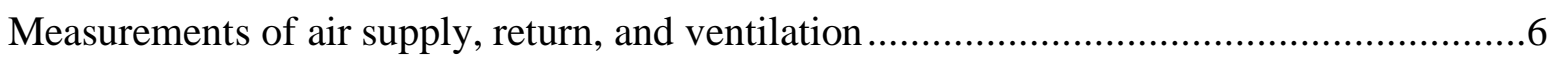

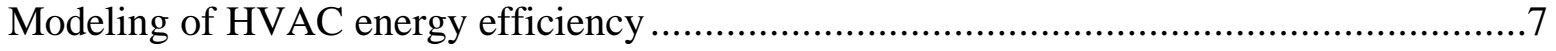

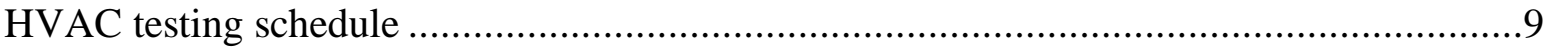

HVAC operation modes and simulated occupancy......................................................

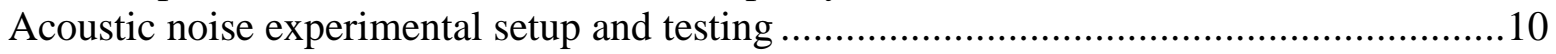

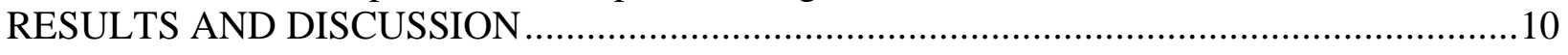

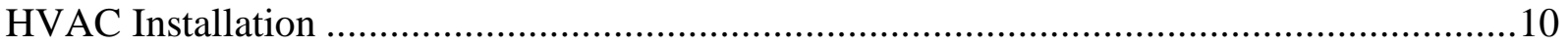

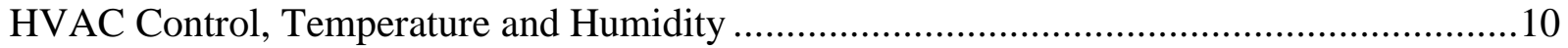

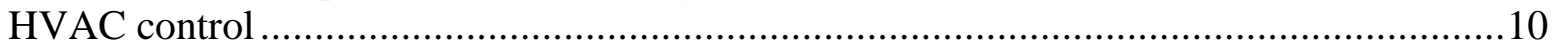

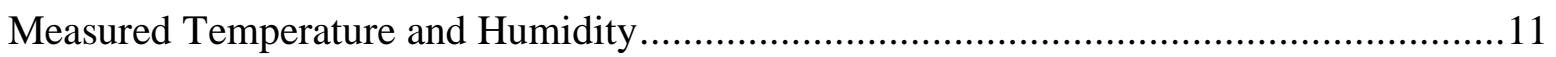

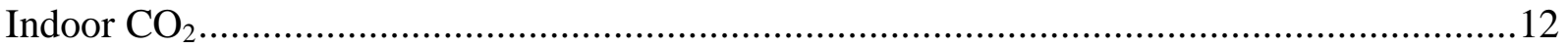

Outdoor Air Supply Rate Measurement ........................................................................12

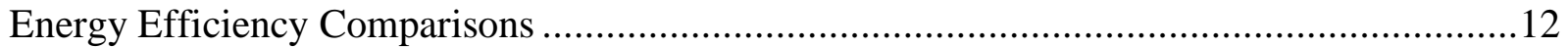

HVAC System Acoustic Noise Comparisons .....................................................................13

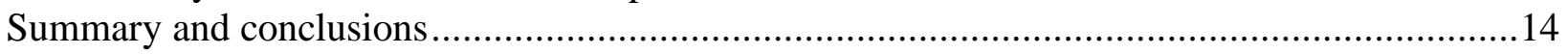

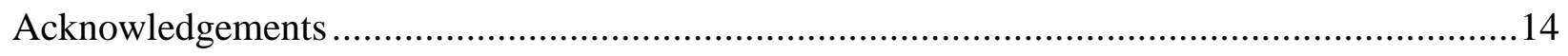

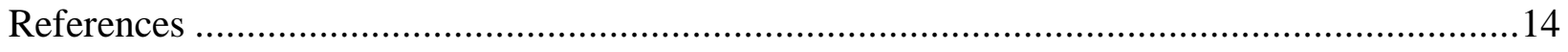

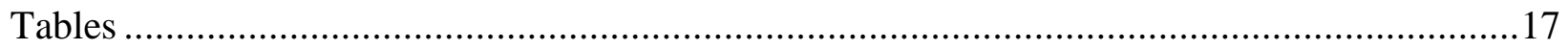

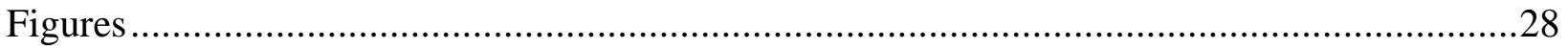


Classroom HVAC: Improving and Saving Energy (IVSE) Laboratory Study

\section{Glossary}

Specific terms and acronyms used throughout this report are defined as follows:

\begin{tabular}{|l|l|}
\hline Acronym & Definition $*$ \\
\hline ASHRAE & American Society of Heating, Refrigeration, and Air Conditioning Engineers \\
\hline CFM & Cubic feet per minute, a measure of ventilation rate per occupant \\
\hline $\mathrm{CO}_{2}$ & Carbon dioxide \\
\hline $\mathrm{dB}(\mathrm{A})$ & A-weighted decibels, measurement of noise level \\
\hline $\mathrm{DOE}$ & United States Department of Energy \\
\hline $\mathrm{hr}^{-1}$ & Units for air exchange rate \\
\hline HPAC & Heat pump air conditioner \\
\hline HVAC & Heating, ventilation, and air conditioning system \\
\hline IEQ & Indoor air and environmental quality \\
\hline IHPAC & Improved heat pump air conditioner \\
\hline IVSE & Classroom HVAC: Improving Ventilation and Saving Energy \\
\hline L & Liters \\
\hline LBNL & Lawrence Berkeley National Laboratory \\
\hline PHPS & Performance of the Heat Pump System \\
\hline RC & Relocatable, or portable or modular, classroom \\
\hline RH & Relative humidity, measured as percentage \\
\hline RMS & Root Mean Square \\
\hline SEER & Seasonal energy efficiency rating \\
\hline
\end{tabular}




\section{ABSTRACT}

The primary goals of this research effort were to develop, evaluate, and demonstrate a practical HVAC system for classrooms that consistently provides classrooms with the quantity of ventilation in current minimum standards, while saving energy, and reducing HVAC-related noise levels. This research was motivated by several factors, including the public benefits of energy efficiency, evidence that many classrooms are under-ventilated, and public concerns about indoor environmental quality in classrooms. This project involved the installation and verification of the performance of an Improved Heat Pump Air Conditioning (IHPAC) system, and its comparison, a standard HVAC system having an efficiency of 10 SEER. The project included the verification of the physical characteristics suitable for direct replacement of existing 10 SEER systems, quantitative demonstration of improved energy efficiency, reduced acoustic noise levels, quantitative demonstration of improved ventilation control, and verification that the system would meet temperature control demands necessary for the thermal comfort of the occupants. Results showed that the IHPAC met these goals. The IHPAC was found to be a direct bolt-on replacement for the 10 SEER system. Calculated energy efficiency improvements based on many days of classroom cooling or heating showed that the IHPAC system is about $44 \%$ more efficient during cooling and 38\% more efficient during heating than the 10 SEER system. Noise reduction was dramatic, with measured A-weighed sound level for fan only operation conditions of $34.3 \mathrm{~dB}(\mathrm{~A})$, a reduction of $19 \mathrm{~dB}(\mathrm{~A})$ compared to the 10 SEER system. Similarly, the IHPAC stage- 1 and stage-2 compressor plus fan sound levels were $40.8 \mathrm{~dB}(\mathrm{~A})$ and $42.7 \mathrm{~dB}(\mathrm{~A})$, reductions of 14 and $13 \mathrm{~dB}(\mathrm{~A})$, respectively. Thus, the IHPAC is 20 to 35 times quieter than the 10 SEER systems depending upon the operation mode. The IHPAC system met the ventilation requirements and was able to provide consistent outside air supply throughout the study. Indoor $\mathrm{CO}_{2}$ levels with simulated occupancy were maintained below $1000 \mathrm{ppm}$. Finally temperature settings were met and controlled accurately. The goals of the laboratory testing phase were met and this system is ready for further study in a field test of occupied classrooms.

\section{INTRODUCTION}

The primary goals of the "Improving Ventilation and Saving Energy" (IVSE) project were to develop, evaluate, and demonstrate a very practical HVAC system for relocatable classrooms (RCs) that consistently provides them with the quantity of ventilation in current minimum standards, while saving energy, and reducing HVAC-related noise levels. The ultimate goal is to provide the specification of this system to the public domain, and stimulate increased use of advanced classroom HVAC in the market through interaction with key school facility stakeholders.

The need for an improved classroom ventilation system is based, in part, on the considerable evidence, summarized in Daisey et al. (1998, 2003), indicating that ventilation rates in classrooms often do not meet the current ASHRAE minimum rate of 15 CFM per occupant (ASHRAE, 2004). While relatively few measurements of actual classroom ventilation rates are available, concentrations of $\mathrm{CO}_{2}$ in classrooms often substantially exceeded $1000 \mathrm{ppm}$; implying ventilation rates less than $15 \mathrm{CFM}$ per occupant, with several studies reporting peak concentrations exceeding $1500 \mathrm{ppm}$, and some concentrations exceeding $3000 \mathrm{ppm}$. In a recent survey of California portable classrooms (also called relocatable classrooms or RCs), $\mathrm{CO}_{2}$ 
concentrations exceeded $1000 \mathrm{ppm}$ in about $40 \%$ of classrooms and concentrations exceeded 2000 ppm in approximately 10\% of classrooms (CARB-DHS 2003). In a survey of 400 classrooms in Washington state and Idaho (Shendell et al. 2004), $\mathrm{CO}_{2}$ concentrations measured at random times in $45 \%$ of classrooms exceeded 1000 ppm, thus, a considerably larger fraction of steady state or peak $\mathrm{CO}_{2}$ concentrations would have exceeded $1000 \mathrm{ppm}$.

Further evidence of low classroom ventilation rates was obtained in a study in 14 California schools (Lagus Applied Technologies 1995). The measured mean minimum air exchange rate was $2.4 \mathrm{~h}^{-1}$, with a range of 1.2 to $2.9 \mathrm{~h}^{-1}$, while the air exchange rate corresponding to the current standard was estimated to be $3 \mathrm{~h}^{-1}$.

Anecdotally, we are aware that ventilation rates in classrooms are often low because teachers frequently operate classroom HVAC systems in the mode where the supply fan shuts off except when heating or cooling is required. Thus, outside air is supplied mechanically only during periods of heating or cooling and the time average rate of supply is below standards. We also observe that teachers use this mode of HVAC system operation to avoid HVAC system-related noise. These anecdotal reports are supported by the findings from the recently completed survey of California RCs. Teachers in $60 \%$ of RCs reported that they sometimes turned off HVAC systems to reduce noise levels (CARB-CDHS 2003). Consequently, the available evidence indicates the importance of reducing HVAC noise in the development of improved classroom HVAC systems.

Several statutes and standard address the provision of adequate ventilation in California classrooms. Continuous ventilation is required in California Classrooms under both state energy and occupational laws (CA Title 24 2001, CCR 1995) and is a required component of ASHRAE Standard 62.1 (ASHRAE 2004).

The relocatable classroom (RC) HVAC industry has been incrementally addressing the classroom noise levels generated by the wall mount heat pump air conditioner (HPAC) that they produce. For example, in the late 1990s Bard Manufacturing Company developed a 12 SEER "Quiet Climate" model to meet specifications from the Los Angeles Unified School District (LAUSD, 1998). This unit was designed to operate at indoor sound levels $\leq 50 \mathrm{~dB}(\mathrm{~A})$ measured at a point $3 \mathrm{~m}\left(10^{\prime}\right)$ from the return grille and $1.5 \mathrm{~m}$ high. This model is the current state of the art, with a relatively small market penetration in California. Unfortunately, $50 \mathrm{~dB}(\mathrm{~A})$ is not currently considered an adequate target for classroom sound levels. The Collaborative on High Performance Schools (CHPS) recommends unoccupied classroom levels to be at or below 45 dB(A) (CHPS 2002). Additionally, the Acoustical Society of America (ASA) provide a guideline for classrooms of $35 \mathrm{~dB}(\mathrm{~A})$ (ASA 2002).

A great deal of energy is used to condition ventilation air in high occupancy spaces such as classrooms. Mudarri et al. (1996) used an energy simulation model and estimated that increasing school building ventilation rates by $10 \mathrm{CFM}$, from 5 to $15 \mathrm{CFM}$ per occupant, would increase annual HVAC energy use by $15 \%, 31 \%$, and $32 \%$ in Miami, Washington, DC, and Seattle, respectively. From these predictions, we can estimate that the energy to provide $15 \mathrm{CFM}$ per student of ventilation is approximately $22 \%, 45 \%$, and $45 \%$ of total classroom HVAC energy in these three climates, respectively. This finding indicates the existence of a clear energy and 
financial penalty from increasing ventilation to meet existing standards if improved energy efficiency is not applied to offset the increased demand.

A number of studies (e.g., Seppanen et al. 1999, Wargocki et al. 2002; Erdmann et al. 2002) have investigated the relationship of ventilation rates to health outcomes (sick building syndrome symptoms, respiratory illnesses), absence rates, and perceived air quality; however, most studies have been performed in office buildings. Some studies have used indoor $\mathrm{CO}_{2}$ concentrations as a surrogate for ventilation rate per occupant. A large majority of these studies have found a worsening of some health, absence, or perceived air quality outcomes at lower ventilation rates or higher $\mathrm{CO}_{2}$ concentrations. Detrimental effects have been particularly clear when ventilation rates are reduced below $20 \mathrm{CFM}$ per occupant and several studies have found benefits of increasing ventilation rates above $20 \mathrm{CFM}$ per occupant. These studies indicate that ventilation rates have important effects on the health of occupants.

When we consider these factors together - the important effects of ventilation on people, the energy used for ventilation, and the evidence of ventilation deficiencies in classrooms, it is very clear that we need to develop and promote use of highly energy efficient systems for providing classroom ventilation.

\section{LABORATORY STUDY OBJECTIVES}

The objectives of this controlled laboratory study were to evaluate the energy, ventilation, and IEQ performance of the advanced HVAC system relative to a standard, widely used, 10 SEER HVAC system. With respect to this laboratory study the specific goals were as follows.

\section{Quantitative Energy Consumption Goal/Expectation}

Demonstrate the reduced energy consumption of the advanced HVAC system in a laboratory setting.

Goal-Quantitatively show in the laboratory that energy consumption reductions are at least $30 \%$ lower than the 10 SEER system or by inference a 10\% improvement compared to the 12 SEER system.

Quantitative Noise Reduction Goal/Expectation

The advanced HVAC system is designed to significantly cut classroom noise levels relative to the Low-Noise 12 SEER system, a major reduction relative to the baseline 10 SEER system.

Goal - The acoustic specification for the 12 SEER HVAC is that it operate in an unoccupied room at $<50 \mathrm{~dB}(A)$ at a distance of 10 feet from the air return, measured five feet above the floor. The advanced system will be conservatively expected to operate at $<45 \mathrm{~dB}(A)$ at the same location in its noisiest operating condition.

Physical System Integration Goals/Expectations

HVAC system meets general physical dimension and integration characteristics suitable for mounting on new and existing relocatable classrooms in California. This requirement is extremely important for market transfer. 
Goal - show dimensionally that advanced unit fits on and can be integrated into new and existing relocatable classrooms.

Quantitative Ventilation System Improvement Goals/Expectations

HVAC system provides sufficient outside air ventilation flow for up to 31 occupants

(ASHRAE standard 62: 465 CFM), continuously

Goal - show quantitatively that system meets 100\% of ASHRAE 62 Standard outside air

supply flow and can provide it continuously

HVAC system controls provide signals to air handler to constantly and continuously ventilate during occupancy irrespective of thermal demand

Goal - show that controls react upon occupancy to provide ventilation. Monitoring will verify that HVAC system ventilation activates upon occupancy demand.

HVAC system maintains indoor $\mathrm{CO}_{2}$ levels below 1000 ppm

Goal - show under simulated classroom occupancy (using $\mathrm{CO}_{2}$ gas cylinders) that $\mathrm{CO}_{2}$ levels can be maintained $<1000$ ppm 100\% of the time given simulated generation from 31 or fewer occupants

HVAC system can provide thermal conditioning at air velocities and temperatures that meet ASHRAE 55 thermal comfort standards (ASHRAE, 2004).

Goal - show that air velocities and supply temperatures lead to acceptable thermal comfort based upon ASHRAE 55. Note that acceptable relative humidity per ASHRAE 55 may not always be met depending upon ambient humidity conditions.

\section{METHODS}

\section{HVAC systems and controls, installation, and commissioning HVAC systems and controls}

The 10 SEER unitary vertical wall-mount HPAC system is the most common and frequently installed HVAC system on RCs in California. Although lower efficiency wall-mount systems are to be found on numerous older RCs, those installed in the last ten years are likely to have a 10 SEER rating. As discussed above, at least one manufacturer has put a similar system on the market that achieves as 12 SEER rating in addition to some attempts to improve the acoustic design. The improved HPAC system (IHPAC) developed in this study maintains the same wallmount configuration and installation form factor while attempting to address perceived design deficits in the areas of energy efficiency, acoustics, ventilation control, thermal control, and refrigerant types. Brief descriptions of the 10 SEER and IHPAC systems are as follows.

10 SEER. The 10 SEER system was designed to meet the then current California state residential energy efficiency standard of 9.7 SEER (CEC 1999). The 10 SEER system installed for this study is Bard Manufacturing Co. packaged unit operating of single-phase 240VAC power. It consists of a single stage reversible heat-pump compressor, with conventional evaporator coil in the supply air stream, and a condenser coil exposed to the outdoor air. The 10 SEER HVAC systems in use operate with standard HCFC refrigerant. The system utilizes two standard fan motors, one for the supply air fan and one for moving air across the condenser coil. The unit includes a classroom ventilator (CRV) with a motor-driven louver situated such that the 
supply air fan draws a set percentage of outside air into the RC and rejects an equal amount of return air from the system. The CRV receives a signal from the HVAC control to open when outdoor air is required, and shut when it is not.

The 10 SEER control can range from a weekly programmable setback timer thermostat to a simple single program type mixed heating and air conditioning thermostat. An additional manual setting on the thermostat allows the teacher to turn on the fan independently if desired, allowing for continuous ventilation. A programmable setback timer was used in this study. The key point regarding this control system is that the CRV louver operation and supply air fan operation are tied to the thermostat setpoint. Thus, air recirculation and outside ventilation air are only provided to the classroom during off-setpoint (i.e., heating or cooling) periods. The 10 SEER HVAC systems were installed and operated using the existing standard that requires that the fan be operated continuously to supply outside air during occupied hours.

IHPAC. LBNL worked with Bard Manufacturing Co. to develop a set of design goals to engineer an improved HPAC system based upon the project goals discussed above. The manufacturer then engineered, fabricated and tested a number of prototypes in their factory. A final functional prototype meeting the manufacturer's design was then shipped to LBNL and installed for testing. The basic layout of the unit is very similar to the 10 SEER system with the following differences. The compressor is more energy efficient and operates in two-stages and uses an alternative to an HCFC refrigerant in anticipation of the $2010 \mathrm{HCFC}$ refrigerant phaseout (USEPA, 2004). The supply air fan motor is an energy efficient electronically commutated type. The condenser and evaporator coils are re-configured to optimize energy efficiency within the constraints of the package size. The entire system was re-engineered to minimize acoustic noise and mechanical vibration.

The IHPAC was installed with an automatic "smart controller". This controller was developed for the IHPAC by Bard Manufacturing as part of this project. It was designed to relieve the responsibility of the teachers of the majority of HVAC operation tasks. Additionally, it decouples the ventilation and thermal aspects of control through the use of an internal infrared motion-detector-type occupancy sensor that triggers ventilation whenever occupants are detected. The control interface is limited to a simple temperature setting adjustment, using uparrow and down-arrow buttons to provide a locked indoor temperature range (set by a technician in the field to $\pm 4.0^{\circ} \mathrm{F}\left(2.5^{\circ} \mathrm{C}\right)$ in this study) in order to accommodate individual comfort differences. The occupancy sensor logic is set to wait 30 minutes after the last observed motion in the RC before setting back the temperature and shutting down the ventilation. It is also desensitized to very short (i.e., one-minute) detection of motion to avoid unneeded operation, but triggers HVAC operation as soon as a valid occupancy is detected. Finally, the system is designed to learn the classroom occupancy schedule over a moving two-week period, and then start anticipating occupancy by pre-conditioning the RC to the settings learned from the teacher's temperature control use patterns. Pre-conditioning also includes a pre-occupancy ventilation purge of three air changes (roughly one hour) as required by California Title 24 .

\section{LBNL RC Test Bed}

A modular, RC, on loan from a major leasing firm, was installed and commissioned at LBNL. Interior and exterior photographic views of the installation and setup may be seen in Figures 1 and 2. The RC consisted of two modular halves, each $3.7 \mathrm{~m}$ (12') by $12 \mathrm{~m}$ (40'), with a ceiling 
height of $2.7 \mathrm{~m}\left(9^{\prime}\right)$, to form an $89 \mathrm{~m}^{2}\left(960 \mathrm{ft}^{2}\right)$ floor. The RC modules were mirror images of each other, each set up with a complete HVAC system and independent electrical system.

Unlike most RCs, this unit did not have any windows since most RCs are manufactured with the window on one module and the HVAC on the opposite module. The RC ceiling consisted of a $60 \mathrm{~cm}$ (24") T-bar grid with typical fiberglass acoustic ceiling tiles.

Both RC modules were delivered with a standard 10 SEER Bard HVAC system with a Bard adjustable classroom ventilator louver system installed internally. The return grille (aprox. 46 $\mathrm{cm}$ by $76 \mathrm{~cm}$ ) of each unit was installed at the standard positions on the rear $7.2 \mathrm{~m}$ long (24') wall, approximately $1.5 \mathrm{~m}$ (5') above floor level. Each system was equipped with a sheet metal supply plenum connected to three $30 \mathrm{~cm}$ (12") insulated flexible supply ducts terminating at three supply diffusers located at approximately 3m (10'), 6m (20’), and 9m (30') from the end wall along the ceiling midpoint of each RC module. The $60 \mathrm{~cm}$ modular supply diffusers transitioned from $30 \mathrm{~cm}$ duct to a $30 \mathrm{~cm}$ square configuration sheet metal-finned discharge area.

One of the 10 SEER HVAC systems was removed after delivery and replaced with a new prototype Bard system (IHPAC) designed to meet the targeted improvements described above. This system also incorporates a classroom ventilator. The IHPAC was ducted similarly to the 10 SEER system, with the exception that the supply diffusers were sized with a $45 \mathrm{~cm}$ (18") square discharge area. The supply diffusers were placed in the same position as those of the 10 SEER units.

\section{Instrumentation}

The instrumentation used in this study is shown in Table 1. Real-time data were stored in an APS datalogger at one-minute intervals and downloaded from the APT datalogger. Total RMS power consumption was measured on each sub-system of the HVAC systems using datalogging power meters. Indoor and outdoor temperature, $\mathrm{RH}$, and $\mathrm{CO}_{2}$ concentrations were measured in the RC continuously. The outdoor monitoring position was under the eves of the RC roof with a radiation shield placed to reduce radiant heating of the temperature sensor. Indoor monitoring was located on a stand placed in the center of the RC at a height of approximately $1.5 \mathrm{~m}\left(5^{\prime}\right)$. Temperature and RH were also monitored in the mid-room supply diffuser and in the return plenum of each HVAC system. Acoustical noise was measured using a hand-held sound level analyzer, with a protocol described below.

\section{Measurements of air supply, return, and ventilation}

Outside air supply flowrates and supply register flowrates were measured using an active flow hood method (Walker et al. 2001). This method consists of coupling a standard hood with a calibrated fan with integral flow meter, and the use of a differential pressure sensor to measure the pressure at the register. With the flow hood in place, the fan is adjusted until the differential pressure equals zero between the room air and interior of the hood at the connection with the register. The calibrated flow measured by the fan is then equal to the supply flow rate. The same process is applied to measure the outside air intake flow and the return flow, although the fan in the measurement system is reversed to supply a positive air pressure rather than a negative pressure. Outside air supply rates (outside air is about $30 \%$ of the total supply air in this recirculating system) were set to $15 \mathrm{CFM}$ per occupant, or $465 \mathrm{CFM}$ to represent a class of 30 
students and one teacher. The three supply registers were be balanced to split the total supply flow equally (about 500 CFM per register).

Air exchange rates were measured using a steady-state method. Two tracers were measured: $\mathrm{CO}_{2}$ and $\mathrm{SF}_{6}$. When using $\mathrm{CO}_{2}$, the air exchange rate was calculated after subtracting the outdoor $\mathrm{CO}_{2}$ concentration, using the $\mathrm{CO}_{2}$ source injection rate.

The steady state tracer method involves injection of $\mathrm{SF}_{6}$ into the classroom at a constant rate using a low-flow pump to supply the pure gas from a multi-layer gas bag and calculating the air exchange rate from the steady state tracer concentration. The $\mathrm{SF}_{6}$ concentrations were measured with a portable Miran Sapphire infrared gas analyzer (Thermo Electron Corp., Waltham MA) with an internal datalogger and $\mathrm{CO} 2$ was measuring using the sensors described in Table 1. With the steady state method, the air exchange rate was calculated using Equation 1.

$\mathrm{a}=\mathrm{S}_{\text {tracer }} /\left[\left(\mathrm{C}_{\mathrm{ss}}-\mathrm{C}_{\text {out }}\right) \mathrm{V}\right]$

Where,

$\mathrm{a}=\quad$ the classroom air exchange rate $\left(\mathrm{h}^{-1}\right)$,

$\mathrm{S}_{\text {tracer }}=$ the tracer gas $\left(\mathrm{CO}_{2}\right.$ or $\left.\mathrm{SF}_{6}\right)$ source rate $\left(\mathrm{m}^{3} \mathrm{~h}^{-1}\right)$,

$\mathrm{C}_{\mathrm{ss}}=$ the measured steady-state concentration of the tracer in the $\mathrm{RC}$,

$\mathrm{C}_{\mathrm{out}}=$ the measured average outdoor concentration of the tracer at the time of indoor steadystate measurements, and

$\mathrm{V}=\quad$ the internal volume of the $\mathrm{RC}\left(\mathrm{m}^{3}\right)$.

The outside air supply rate $\left(\mathrm{m}^{3} \mathrm{~h}^{-1}\right)$ measured in this fashion is merely:

$\mathrm{Q}=\mathrm{Va}$

The source injection rates of $\mathrm{CO}_{2}$ and $\mathrm{SF}_{6}$ were set to $0.147 \mathrm{~m}^{3} \mathrm{~h}^{-1}\left(2450 \mathrm{ml} \mathrm{min}^{-1}\right)$ and $7.5 \times 10^{-4}$ $\mathrm{m}^{3} \mathrm{~h}^{-1}\left(12.5 \mathrm{ml} \mathrm{min}^{-1}\right)$, respectively. Due to instrument failure during the March 2005 testing period no usable $\mathrm{CO}_{2}$ or $\mathrm{SF}_{6}$ data were collected.

\section{Modeling of HVAC energy efficiency}

The mathematical model used in this study to compare the energy efficiency of the IHPAC to the standard 10 SEER HVAC system is as follows. A stream of air with flow rate $Q_{r}\left(\mathrm{~m}^{3} / \mathrm{sec}\right)$, at $T_{\mathrm{r}}$ $\left({ }^{\circ} \mathrm{C}\right)$ dry-bulb temperature and $\phi_{\mathrm{r}}(\% \mathrm{RH})$, is returned and mixed with a stream of outdoor air with flow rate $\mathrm{Q}_{\mathrm{o}}\left(\mathrm{m}^{3} / \mathrm{sec}\right)$ at $\mathrm{T}_{\mathrm{o}}\left({ }^{\circ} \mathrm{C}\right)$ dry-bulb temperature and $\phi_{\mathrm{o}}(\% \mathrm{RH})$. The resulting mixture is then processed through the heat pump and supplied into the indoor. The supply air flow rate $\mathrm{Q}_{\mathrm{s}}\left(\mathrm{m}^{3} / \mathrm{sec}\right)$, is at $\mathrm{T}_{\mathrm{s}}\left({ }^{\circ} \mathrm{C}\right)$ dry-bulb temperature and $\phi_{\mathrm{s}}(\% \mathrm{RH})$.

The total amount of cooling (indoor heat withdrawn) and heating (indoor heat addition), performed by the heat pump, can be calculated as shown in equation (3). The required properties $\left(\mathrm{m}_{\mathrm{i}}, \mathrm{h}_{\mathrm{i}}\right)$ come from the measured $\mathrm{T}_{\mathrm{i}}, \phi_{\mathrm{i}}$, and $\mathrm{Q}_{\mathrm{i}}(\mathrm{i}=\mathrm{o}$ (outdoor), $\mathrm{s}$ (supply), $\mathrm{r}($ room)) as shown in equations (4) (9). 
Total performed cooling or heating $=\int \mathrm{m}_{\mathrm{r}}\left|\mathrm{h}_{\mathrm{r}}-\mathrm{h}_{\mathrm{s}}\right| d t+\int \mathrm{m}_{\mathrm{o}}\left|\mathrm{h}_{\mathrm{o}}-\mathrm{h}_{\mathrm{s}}\right| d t$

Where

$$
\text { when } \mathrm{T}_{\mathrm{r}}>\mathrm{T}_{\mathrm{o}} \text { (heating) or } \mathrm{T}_{\mathrm{r}}<\mathrm{T}_{\mathrm{o}} \text { (cooling). }
$$

$\mathrm{t}$ is the time variable

$m_{i}=\frac{Q_{i}}{v_{i}}(\mathrm{~kg} \mathrm{sec}-1)$

$\mathrm{Q}_{\mathrm{i}}=$ volumetric flow rate at the point $\mathrm{i}\left(\mathrm{m}^{3} \mathrm{sec}^{-1}\right.$, measured property in this study),

$v_{i}=$ specific volume of the moist air at point $\mathrm{i}\left(\mathrm{m}^{3} \mathrm{~kg}^{-1}\right)$,

$\boldsymbol{v}_{i}=\frac{R a T_{i}}{P}\left(1+1.6078 w_{i}\right)$

$\mathrm{R}_{\mathrm{a}}=$ universal gas constant $8.31441 \mathrm{KJ} \mathrm{Kg}^{-1} \mathrm{~mol}^{-1} \mathrm{~K}^{-1}$,

$\mathrm{T}_{\mathrm{i}}=$ absolute temperature at point $\mathrm{i}\left({ }^{\circ} \mathrm{K}\right.$, measured property in this study),

$\mathrm{P}=$ total pressure $(\mathrm{Pa})$

$\mathrm{W}_{\mathrm{i}}=$ humidity ratio of the moist air at point $\mathrm{i}$ ( $\mathrm{Kg}$ water vapor per $\mathrm{Kg}$ dry air),

$w_{i}=0.62198 \frac{P_{w i}}{P-P_{w i}}$,

$P_{w i}=$ partial pressure of the vapor at point $\mathrm{i}(\mathrm{Pa})$,

$\mathrm{P}_{\mathrm{wi}}=\phi_{\mathrm{i}} \mathrm{P}_{\mathrm{wsi}}$

$\phi_{\mathrm{i}}=$ relative humidity at point $\mathrm{i}$, (dimensionless, measured property in this study)

$\mathrm{P}_{\mathrm{wsi}}=$ saturation pressure of water vapor at point $\mathrm{i}(\mathrm{Pa})$,

$\mathrm{P}_{\mathrm{wsi}}=\exp \left(\mathrm{C}_{8} / \mathrm{T}_{\mathrm{i}}+\mathrm{C}_{9}+\mathrm{C}_{10} \mathrm{~T}_{\mathrm{i}}+\mathrm{C}_{11} \mathrm{~T}_{\mathrm{i}}^{2}+\mathrm{C}_{12} \mathrm{~T}_{\mathrm{i}}^{3}+\mathrm{C}_{13} \ln \left(\mathrm{T}_{\mathrm{i}}\right)\right)$, and where

$\mathrm{C}_{8}=-5800.2206$,

$\mathrm{C}_{9}=1.3914993$

$\mathrm{C}_{10}=-0.04860239$,

$\mathrm{C}_{11}=0.41764768 \cdot 10^{-4}$,

$\mathrm{C}_{12}=-0.14452093 \cdot 10^{-7}$,

$\mathrm{C}_{13}=6.5459673$, and where

$\mathrm{h}_{\mathrm{i}}=\mathrm{t}_{\mathrm{i}}+\mathrm{w}_{\mathrm{i}}\left(2501+1.805 \mathrm{t}_{\mathrm{i}}\right)$, with

$\mathrm{h}_{\mathrm{i}}=$ the moist air enthalpy at point $\mathrm{i}\left(\mathrm{KJ} \mathrm{Kg}^{-1}\right.$ dry air),

$\mathrm{t}_{\mathrm{i}}=$ dry-bulb temperature at point $\mathrm{i}\left({ }^{\circ} \mathrm{C}\right.$, measured property in this study).

The overall performance of an installed heat pump system can be described by a Performance of the Heat Pump System (PHPS). PHPS is defined as the total amount of cooling and heating divided by the total electricity consumption in operating a heat pump.

PHPS $=\frac{\text { total cooling and heating }}{\text { total electricity consumed by the heat pump }}$

PHPS measures how much cooling or heating is provided for each unit of electricity energy consumed. This metric incorporates the comprehensive results of the heat pump performance, 
thermal performance of the building envelope, indoor flow effectiveness, and the controllers' performance.

\section{HVAC testing schedule}

In order to test both the 10 SEER system and the IHPAC system in both heating and cooling modes it was necessary to conduct tests in both cooling and heating seasons. The study began with testing of the 10 SEER HVAC system in September 2004. Unfortunately, due to delays, delivery schedules, and weather, only a few days of cooling data were collected for the 10 SEER system prior to installation of the IHPAC. Again, only a few days of cooling data were collected on the IHPAC system prior to a change in weather. The IHPAC was operated on a continual basis from September 27 to November 24. Some days of mixed heating and cooling occurred. In March of 2005 more 10 SEER data were collected with both heating and cooling periods.

\section{HVAC operation modes and simulated occupancy}

The 10 SEER system was operated in the recommended operation mode with the outside air ventilation fan on continuously and heat pump compressor operating on demand from the thermostat. The thermostat was scheduled to turn on in the morning at 8:00 AM and off at 3:30 PM. The IHPAC was operated using the Bard automatic controller described above. Thus, the outside air ventilation fan operated based on simulated occupancy as discussed below.

In order to simulate student occupancy, timers were set up to control a number of functions on a pre-set schedule: sensible heat generation, carbon dioxide generation, and occupancy. The classroom had a standard desk layout using two rows of three $76 \mathrm{~cm}$ (30") by $2.4 \mathrm{~m}$ (8') tables centered in the middle of the classroom. Thirty $60 \mathrm{~W}$ light bulbs, connected to a timer, were placed along the length of the tables to simulate the heat load of thirty students. A pipe with sections of porous tubing (1/2" drip irrigation tubing) was run along the table above the light bulbs, connected to a cylinder source of pure $\mathrm{CO}_{2}$ metered into a mixing chamber through a mass flow controller. On signal from the timer, the air pump mixed the $\mathrm{CO}_{2}$ with room air and pumped it through the porous tubing. The source rate of $\mathrm{CO}_{2}\left(2450 \mathrm{ml} \mathrm{min}{ }^{-1}\right)$ was selected to simulate respiration from 30 students. Due to instrument failure during the March 2005 testing period no usable $\mathrm{CO}_{2}$ data were collected.

The IHPAC control system senses occupancy with an infrared occupancy sensor. To trigger the occupancy sensor at the desired times, a mirror mounted on a motor revolving at about 6 RPM was used to reflect light off of a heat lamp. The motor and lamp were actuated using a timer as well. The controller reliably sensed occupancy conditions when the infrared heat signal from this assembly was turned on.

The timer schedule was set to Monday through Friday from 8:00h to 14:00h. A 45 minute lunch break at noon, and two fifteen minute recess breaks at 10:00 and 13:30h were included when occupancy was set to zero by turning off the timer switch. During these times the IHPAC occupancy sensor reported no occupancy, and the $\mathrm{CO}_{2}$ injection and light bulbs were turned off. The 10 SEER system was not turned off during these breaks, so its operation was dependent upon the thermal loads in the RC. 


\section{Acoustic noise experimental setup and testing}

Acoustic noise levels in the RC were measured for both the 10 SEER and IHPAC units under a range of operational modes and conditions. In addition, the 10 SEER HVAC unit was operated and tested using two experimental sound abatement approaches: an on-site fabricated return wall sound plenum, and a Bard prototype sound curb. These are described more fully below.

The sound measurement protocol consisted of measuring the acoustic spectra of sound pressure levels at distance of 3, 6, and 9 meters (10', 20', and 30') from (and perpendicular to) the rear wall of the RC and at a distance of 3 meters at a angle of 45 degrees off of the rear wall, all at a height of $150 \mathrm{~cm}\left(5^{\prime}\right)$. The sound pressure spectra were measured at these locations under the following conditions: all devices in the RC turned off, lights on only, the HVAC outdoor air fan on only, the HVAC fans and compressor on, and in the case of the IHPAC, the fans and compressor on in second stage mode. The measurements were conducted both with lights on, and with lights off. A full set of measurements were also collected at a height of $91 \mathrm{~cm}\left(3^{\prime}\right)$, but the sound levels were very close to those at $150 \mathrm{~cm}$, so these measurements were discontinued. The sound level measurements that are presented in this paper are from the lights-off conditions for the purpose of inter-comparison between the different systems and modes.

Sound pressure spectra were measured with and without weighting. Noise Criteria (NC) values (ASHRAE, 2005) were calculated from un-weighted measured sound pressures. A-weighted sound pressures $(\mathrm{dB}(\mathrm{A}))$ were recorded using the $\mathrm{B} \& \mathrm{~K}$ sound level meter's internal software. Measured $\mathrm{dB}(\mathrm{A})$ and $\mathrm{NC}$ levels are both presented in this paper as they are the two most commonly used metrics for assessing indoor noise level conditions in classrooms and other occupied indoor environments.

\section{RESULTS AND DISCUSSION HVAC Installation}

The IHPAC system was installed at the LBNL RC test bed in September 2004. To make room for the IHPAC, one of the two existing 10 SEER systems and the associated supply plenum was removed and stored for future replacement. The IHPAC and its supply plenum were installed on the existing wall with no alterations to the framing, siding, or interior wall. The replacement was an exact fit and the return register did not need to be moved or altered. No power wiring changes were required. New wiring for the smart control system was required, but was not an involved installation.

\section{HVAC Control, Temperature and Humidity}

\section{HVAC control}

The 10 SEER HVAC control worked as designed. During the daily-simulated occupancy periods with 10 SEER operation, the thermostat was set to manual fan in order to simulate the Title 24 requirement for continuous ventilation during occupancy. No problems in function were observed. The IHPAC system smart controller was somewhat problematic during the entire laboratory study. The basic functions worked as expected: Thermal control, occupancy sensing to control outdoor air supply, and the learned pre-occupancy ventilation purge worked without problems. However, during the heating season the smart controller was observed to switch to cycle heating on during the night when indoor temperatures were not below the setback temperature $\left(55^{\circ} \mathrm{F}\right)$. This problem led to frequent heating of the $\mathrm{RC}$ during the nighttime. For 
this reason, the energy analyses below are provided for both school day and 24-hour time periods. Note that this problem was subsequently traced to the value of a time constant in the smart controller software and has been fully remedied, however this fix did not occur until the field study component of this project was under way.

\section{Measured Temperature and Humidity}

Table 2 presents measured temperature data for each study school day (08:00 to 15:00h periods) in the RC for both the 10 SEER and IHPAC HVAC systems. The tables also show whether the HVAC system was operating in cooling, heating, or mixed heating and cooling mode (i.e., heating in AM and cooling in PM). Measurement statistics include average, standard deviation, minimum and maximum values. Across both HVAC systems, the school day average indoor temperatures during cooling days ranged from $71.6^{\circ} \mathrm{F}$ to $78.0^{\circ} \mathrm{F}$ with an average across the study of $75.4^{\circ} \mathrm{F}$. Similarly, for heating, the temperature range was $69.8^{\circ} \mathrm{F}$ to $75.0^{\circ} \mathrm{F}$ with an average across the study of $71.8^{\circ} \mathrm{F}$. During days with mixed heating and cooling the temperature range was $70.3^{\circ} \mathrm{F}$ to $75.1^{\circ} \mathrm{F}$ with an average across the study of $73.1^{\circ} \mathrm{F}$. Average school day outdoor temperatures ranged from $58.7^{\circ} \mathrm{F}$ to $80.1^{\circ} \mathrm{F}, 59.0^{\circ} \mathrm{F}$ to $65.5^{\circ} \mathrm{F}$, and $55.9^{\circ} \mathrm{F}$ to $71.7^{\circ} \mathrm{F}$ for cooling, heating and mixed-mode conditioning, respectively. Averaged school day average indoor temperatures during 10 SEER and IHPAC cooling operation days were within $1.5^{\circ} \mathrm{F}$, and a Student's t-test indicated that the temperature distributions were not statistically different $(\mathrm{p}<0.05)$. During heating mode test days, average school day indoor temperatures were within $0.5^{\circ} \mathrm{F}$ but were statistically different $(\mathrm{p}>0.05)$. Further details may be seen or calculated from complete data in Table 2.

Temperature control appeared to be adequate in both systems, with average temperatures falling close to the set points of $75^{\circ} \mathrm{F}$ for cooling and $72^{\circ} \mathrm{F}$ for heating. The differences seen between systems are likely to be due to slight differences in operation and calibration of thermostats. Certainly thermal comfort due to temperature alone would not be different between the two HVAC systems based on the data collected.

Similarly, Table 3 presents measured RH data for each study school day in the RC for both the 10 SEER and IHPAC HVAC systems. Across both HVAC systems, the school day average indoor RH during cooling days ranged from $22.3 \%$ to $52.0 \%$ with an average across the study of $39 \%$. Similarly, for heating, the RH range was $24.2 \%$ to $52 \%$ with an average across the study of $44.3 \%$. During days with mixed heating and cooling the $\mathrm{RH}$ range was $35.1 \%$ to $52.1 \%$ with an average across the study of $46 \%$. Average school day outdoor RH ranged from $21.8 \%$ to $89.9 \%, 34.4 \%$ to $95.5 \%$, and $45.5 \%$ to $86.9 \%$ for cooling, heating and mixed-mode conditioning, respectively. Mean school day average RH during 10 SEER (42\% RH) and IHPAC (30.5\% RH) cooling operation days were different by almost $12 \% \mathrm{RH}$, and a Student's t-test indicated that their RH distributions were statistically different $(\mathrm{p}>0.05)$. During heating mode test days, the average school day RH was much closer (10 SEER $=45.9 \%$; IHPAC $=43.7 \%)$, within $<3 \% \mathrm{RH}$ but were still statistically different $(\mathrm{p}>0.05)$. Further details may be seen or calculated from complete data in Table 3.

That the average indoor RH was so different between HVAC systems during cooling mode periods was due to a greater difference in outdoor RH during the different testing periods. The corresponding average school day outdoor RH was $55.2 \%$ and $38.4 \%$ for the 10 SEER and 
IHPAC, respectively. In contrast, the mean school day average outdoor RH levels were $73.7 \%$ and $75.4 \%$ during heating mode periods for the 10 SEER and IHPAC, respectively. As would be expected when using a vapor compression system, some water is removed from the conditioned air during cooling, reducing the absolute humidity in the supply air. The reader should bear in mind that during these tests only sensible load, and no latent load, was added during the "occupied" time periods. Thus a real comparison of thermal comfort that includes the humidity component is not addressed here. These comparisons will be available in the field component of this project.

\section{Indoor $\mathrm{CO}_{2}$}

Table 4 summarizes school day statistics for Indoor $\mathrm{CO}_{2}$ measured at the center of the $\mathrm{RC}$ at a height of $1.5 \mathrm{~m}$. With the exception of one day (10/19) the mean school day average $\mathrm{CO}_{2}$ concentration during IHPAC operation was $493 \pm 45 \mathrm{ppm}$ and the minimum and maximum average concentrations were 390 and 560 ppm, respectively. The only 10 SEER measurements captured in this table are for $9 / 15 / 04$, and the $\mathrm{CO}_{2}$ concentrations for that day are consistent with those from the IHPAC dates. On three days $(10 / 18,11 / 17, \& 11 / 18)$ the outdoor air supply was turned off during part of the day leading to elevated $\mathrm{CO}_{2}$ concentrations.

\section{Outdoor Air Supply Rate Measurement}

Table 5 summarizes the outdoor, and HVAC supply and return $\mathrm{CO}_{2}$ concentrations for each study school day period where data were recorded, as well as calculated outside air flow rates calculated using Equation 2. These data are consistent with those in Table 4 in terms of concentration, and have been used primarily for calculation of outside air supply rates for verification of the IHPAC ventilation and for energy analyses. As discussed above, both the 10 SEER and IHPAC systems were adjusted to provide 480 CFM (32 occupants * 15 CFM occupant $^{-1} ; 2241 \mathrm{sec}^{-1}=806 \mathrm{~m}^{3} \mathrm{~h}^{-1}$ ), based upon the California Title 24 and ASHRAE 62.1 ventilation standards. The average outside airflow rates (excluding the three dates discussed above) based on these measurements are $492 \pm 76$ CFM $\left(837 \pm 129 \mathrm{~m}^{3} \mathrm{~h}^{-1}\right)$, very close to the rates set using a duct flow hood during installation.

Table 7 provides a summary of measured indoor and outdoor $\mathrm{SF}_{6}$ tracer gas concentrations. As with the $\mathrm{CO}_{2}$ tracer, $\mathrm{SF}_{6}$ was used to measure ventilation rates. Calculated outdoor air supply rates (excluding the 10/18/04 measurements) for the study IHPAC study dates averaged 497 \pm 31 CFM $\left(845 \pm 53 \mathrm{~m}^{3} \mathrm{~h}^{-1}\right)$, on average within $1 \%$ of the rates measured using $\mathrm{CO}_{2}$ as a tracer.

\section{Energy Efficiency Comparisons}

Table 8 lists daily-calculated PHPS values for the 10 SEER and IHPAC systems calculated as discussed above using Equation 10. Table 9 summarizes these data, showing estimated system efficiencies for the 10 SEER and IHPAC units. Study days with zero or minimal conditioning loads were not included in these analyses. Data are presented both for conditioning loads over the school-day hours and for each 24-hour study day. Due to night-time heating conditions on many days the 24-hour conditioning energy loads and consumption were considerably greater than those for the school-day periods. The 10 SEER unit PHPS values were 2.4 and 3.3 for cooling and heating, respectively. The IHPAC system PHPS corresponding values were 4.3 and 5.2, respectively. The ratio of 10 SEER to IHPAC school day PHPS values were 0.56 for cooling and 0.63 for heating, and 0.59 overall. Using this approach the we find that the 
efficiency of the IHPAC is about $44 \%$ more efficient during cooling and $37 \%$ more efficient during heating than the 10 SEER system.

The PHPS ratio calculated across all (heating and cooling) measurements should be interpreted with caution since it is comprised of a mix of heating and cooling data that is not weighted in any way. Since many more days of heating measurements are in the dataset the ratio is skewed towards the heating mode.

Figure 3 is a plot of the amount of heat and cooling provided by the 10 SEER and IHPAC HVAC systems during school day periods calculated as described in Equation 3 above, plotted versus school day measured HVAC electricity consumption. Figure 4 plots a similar set of data for daily 24-hour monitoring periods. The least square regression fits of these data are tabulated in Table 10. The regression data show good-to-excellent fits. The regression line slopes are the best-fit relationship equivalent to PHPS. The ratio of 10 SEER system slopes to IHPAC slopes are compared to their analogous PHPS ratios in the table. Not surprisingly, they are very similar, differing by only a few percent.

The 24 hour energy efficiency calculations are all presented in the tables and figures, but should be interpreted with some caution because the 10 SEER system was never operated during the nighttime while the IHPAC was regularly operated for nighttime heating due to a controller software bug. These data are provided for completeness. It should also be noted that the enthalpy calculation method used in this analysis accounts for the thermal conditions of the RC structure such that the nighttime conditioning of the space is accounted for in the daytime energy balance.

\section{HVAC System Acoustic Noise Comparisons}

Table 11 summarizes acoustic noise levels measured during operation of the 10 SEER and IHPAC HVAC systems, as well as the two additional acoustic experiments when the prototype sound wall and prototype sound curb were tested. Octave band sound pressure levels $(\mathrm{dB})$ for the test conditions and measurement position are included. This discussion will focus on the position $3 \mathrm{~m}\left(10^{\prime}\right)$ from the HVAC return and $1.5 \mathrm{~m}\left(5^{\prime}\right)$ above the floor. This position is frequently used by the RC industry and school facilities stakeholders as a test reference point for comparison. The $3 \mathrm{~m}$ x 45 degree, $6 \mathrm{~m}$, and $12 \mathrm{~m}$ measurement locations listed have consistently lower sound levels in these tests as would be expected since they are at a greater distance from the HVAC system.

The measured A-weighed sound level [NC value] for fan only operation conditions for the 10 SEER and IHPAC systems were 53.5 dB(A) [NC-45] and $34.3 \mathrm{~dB}(\mathrm{~A})$ [NC-25], respectively. Similarly, during the operation of the 10 SEER system compressor plus fan, and the IHPAC stage- 1 compressor plus fan, sound levels were $55.2 \mathrm{~dB}(\mathrm{~A})$ [NC-55] and $40.8 \mathrm{~dB}(\mathrm{~A})$ [NC-35], respectively. During stage- 2 plus fan operation the IHPAC sound level increased to $42.7 \mathrm{~dB}(\mathrm{~A})$ [NC-40]. Thus, the IHPAC system noise reduction was about $19 \mathrm{~dB}(\mathrm{~A}), 14 \mathrm{~dB}(\mathrm{~A})$, and 13 $\mathrm{dB}(\mathrm{A})$ for fan, stage-1, and stage-2, respectively. In terms of sound intensity the IHPAC fan noise is about 35 times quieter than the 10 SEER fan. Likewise the IHPAC compressor first and second stages are about 22 times and 20 times quieter than the 10 SEER system compressor, respectively. The sound wall and sound curb systems substantially reduced the noise levels from the 10 SEER system, but not to the low noise levels of the IHPAC. 


\section{Summary and conclusions}

The installation and verification of the performance of the Improved HPAC (IHPAC) system, and its comparison the standard 10 SEER HVAC system was fully successful and suggested that the new system meets the goals set out for this project. These goals included the verification of physical characteristics suitable for direct replacement of existing 10 SEER systems, quantitative demonstration of improved energy efficiency, reduced acoustic noise levels, quantitative demonstration of improved ventilation control, and that it meets temperature control demands necessary for the thermal comfort of the occupants.

The results of this extensive testing showed that with the exception of one small, and subsequently corrected problem that the IHPAC met these goals. The IHPAC was found to be a direct bolt-on replacement for the 10 SEER system. Calculated energy efficiency improvements based on many days of testing showed that the IHPAC system is about $44 \%$ more efficient during cooling and $38 \%$ more efficient during heating than the 10 SEER system. Noise reduction was dramatic, with measured $\mathrm{A}$-weighed sound level for fan only operation conditions of $34.3 \mathrm{~dB}(\mathrm{~A})$, a reduction of $19 \mathrm{~dB}(\mathrm{~A})$ compared to the 10 SEER system. Similarly, the IHPAC stage- 1 and stage- 2 compressor plus fan sound levels were $40.8 \mathrm{~dB}(\mathrm{~A})$ and $42.7 \mathrm{~dB}(\mathrm{~A})$, reductions of 14 and $13 \mathrm{~dB}(\mathrm{~A})$, respectively. Thus, the IHPAC is 20 to 35 times quieter than the 10 SEER systems depending upon the operation mode. The IHPAC system met the ventilation requirements and was able to provide consistent outside air supply throughout the study. Indoor $\mathrm{CO}_{2}$ levels with simulated occupancy were maintained below $1000 \mathrm{ppm}$. Finally temperature settings were met and controlled accurately. As discussed above, the only problem to arise was that the IHPAC software was causing the system to heat during unoccupied nighttime periods. This problem was subsequently solved and remedied in the field study. The goals of the laboratory testing phase were met and this system is ready for further testing in a field study of occupied classrooms.

\section{Acknowledgements}

We would like to acknowledge Maury Tiernan of Geary Pacific Supply for his tireless technical support and sharing of RC HVAC expertise. We also thank Scott Alexander of Mobile Modular Management for arranging the loan of the RC test bed for the study. Thanks also to Richard Diamond and Peng $\mathrm{Xu}$ of LBNL for their reviews of this manuscript. This research was sponsored by the California Energy Commission through the Public Interest Energy Research program as the Lawrence Berkeley National Laboratory Classroom HVAC: Improving Ventilation and Saving Energy research project, CEC Contract Number 500-03-041. The study was additionally supported by the Assistant Secretary for Energy Efficiency and Renewable Energy, Building Technology Program of the U.S. Department of Energy under contract DEAC02-05CH11231

\section{References}

ASA 2002. "Acoustical Performance Criteria, Design Requirements, and Guidelines for Schools." ANSI S12.60-2002. Acoustical Society of America. Melville, NY 11747 
ASHRAE, 2005. ASHRAE Handbook-Fundamentals, "Chapter 7: Sound and Vibration," Atlanta: American Society of Heating, Refrigerating and Air-Conditioning Engineers, Inc., Atlanta

ASHRAE, 2004. ANSI/ASHRAE 55-2004 ASHRAE standard, Thermal Environmental Conditions for Human Occupancy, Atlanta: American Society of Heating, Refrigerating and AirConditioning Engineers, Inc., Atlanta.

ASHRAE. American Society of Heating, Refrigerating, and Air Conditioning Engineers (ASHRAE). 2004. ANSI/ASHRAE 62, Ventilation for acceptable indoor air quality. American Society of Heating, Refrigerating and Air-Conditioning Engineers, Inc., Atlanta.

California Title 24, 2001. California Building Standards, Title 24-Energy Efficiency, part six. California Energy Commission, Sacramento, CA.

CARB/CDHS. 2003. "Report to the California Legislature. Environmental Health Conditions in California's Portable Classrooms." California Air Resources Board and the California Department of Health Services. Sacramento CA.

CCR 1995. California Code of Regulations, Occupational Safety and Health Codes for nonresidential buildings, Title 8 .

CEC 1999. Energy Efficiency Standards for Residential and Non-Residential Buildings. P40098-001. California Energy Commission, Sacramento, CA

Collaborative for High Performance Schools (CHPS). 2002. "HVAC Best Practices Manual." CHPS Inc. http://www.chps.net/manual/index.htm

Daisey, J and Angel, WJ. A Survey and Critical Review of the Literature on Indoor Air Quality, Ventilation, and Health Symptoms in Schools. Berkeley, CA: Ernest Orlando Lawrence Berkeley National Laboratory, Environmental Energy Technologies Division, Indoor Environment Department, March 1998. LBNL-41517

Daisey, J.M., W.J. Angel, and M.G. Apte (2003). Indoor Air Quality, Ventilation and Health Symptoms in Schools: An Analysis of Existing Information. Indoor Air, 13(1):53-64

Erdmann, C.A., Steiner, K.C,, Apte, M.G., (2002) "Indoor carbon dioxide concentrations and SBS symptoms in office buildings revisited: Analyses of the 100 building BASE Study dataset". Proceedings of Indoor Air 2002 Conference, Monterey, CA, Vol. 3, pp. 443-448. Indoor Air 2002, Santa Cruz, CA

Lagus Applied Technologies. 1995. Air Change Rates in Non-Residential Buildings in California. Report P400-91-034BCN, Prepared for the California Energy Commission by Lagus Applied Technology, Inc., San Diego, California. 
LAUSD. 1998. "LAUSD Specifications for Air Conditioning Systems (Wall Mount Heat Pump). Specifications data 7/5/98." Los Angeles Unified School District, Los Angeles CA.

Mudarri, D, Hall JD, and Welling E. 1996. Energy cost and IAQ performance of ventilation systems and controls. Proceedings of IAQ'96 Paths to Better Building Environments, pp 151160. ASHRAE, Atlanta, GA.

Seppanen, O.A., Fisk, W.J., and Mendel, M.J. (1999) Association of ventilation rates and $\mathrm{CO}_{2}$ concentrations with health and other human responses in commercial and institutional buildings. Indoor Air 9: 226-252.

Shendell DG, Pill R, Fisk WJ, Apte MG, Blake D, Faulkner D (2004) Associations between classroom $\mathrm{CO}_{2}$ concentrations and student attendance. Indoor Air, 14 (3) 333-41.

USEPA. 2004. "40 CFR Part 82. Protection of Stratospheric Ozone: Allowance System for Controlling HCFC Production, Import and Export; Direct Final Rule and Proposed Rule." Federal Register 69(116):34024-34033.

Wargocki P et al. (2002) Ventilation and health in non-industrial indoor environments: report from a European multidisciplinary scientific consensus meeting (EUROVEN). Indoor Air 12: 113-128.

Walker, I.S., Wray, C.P., Dicker off, D.J., and Sherman, M.H. 2001. Evaluation of flow hood measurements for residential register flows. LBNL-47382, Lawrence Berkeley National Laboratory, , Berkeley, CA 94720. 
Classroom HVAC: Improving and Saving Energy (IVSE) Laboratory Study

Tables

Table 1 . The field study instrumentation.

\begin{tabular}{|c|c|c|c|c|c|}
\hline Parameters & Instrument & Location & Accuracy & Precision & Range \\
\hline Power & $\begin{array}{l}\text { Optimum } \\
\text { Energy } \\
\text { Products, } \\
\text { ElitePRO }\end{array}$ & $\begin{array}{l}\text { 10SEER and } \\
\text { IHPAC } \\
\text { systems }\end{array}$ & $\begin{array}{l}<1 \% \text { of reading, exclusive } \\
\text { of sensor accuracy }\end{array}$ & $\begin{array}{l}12 \text { bit (1 part in 4,096); } 0.1 \\
\text { Volt, 0.01 Amp, 1 Watt, } 1 \\
\text { VAR, } 1 \text { VA, 0.01 PF }\end{array}$ & $\begin{array}{l}4 \text { channels of current, } \\
0-6000 \mathrm{~A} \text {. } \\
3 \text { channels of voltage, } \\
0-600 \mathrm{~V} \text { ac or dc. }\end{array}$ \\
\hline RH, Temperature & $\begin{array}{l}\text { The Energy } \\
\text { Conservatory, } \\
\text { Automated } \\
\text { Performance } \\
\text { Testing (APT) } \\
\text { System }\end{array}$ & $\begin{array}{l}\text { Ceiling } \\
\text { Supply } \\
\text { Return } \\
\text { Outside }\end{array}$ & $\begin{array}{l}\text { Temperature: } \\
+/-0.25^{\circ} \mathrm{C}\left(0{ }^{\circ} \mathrm{C} \text { to } 75{ }^{\circ} \mathrm{C}\right) \text {, } \\
+/-0.5{ }^{\circ} \mathrm{C}\left(<0{ }^{\circ} \mathrm{C},>75{ }^{\circ} \mathrm{C}\right) \\
\mathrm{RH}:+/-5 \%(0 \text { to } 60 \% \mathrm{RH}) \text {, } \\
+/-8 \% \mathrm{RH} \text { at } 90 \% \mathrm{RH} \\
\left.\text { (@ } 25{ }^{\circ} \mathrm{C} \text {, noncondensing }\right)\end{array}$ & $\begin{array}{l}0.025^{\circ} \mathrm{C} @-40{ }^{\circ} \mathrm{C}, \\
0.05{ }^{\circ} \mathrm{C} @ 21{ }^{\circ} \mathrm{C} \\
1.0{ }^{\circ} \mathrm{C} @ 100{ }^{\circ} \mathrm{C}\end{array}$ & $\begin{array}{l}\text { Temperature: }-40{ }^{\circ} \mathrm{C} \text { to } \\
100{ }^{\circ} \mathrm{C} \\
\text { RH: } 0 \text { to } 100 \% \mathrm{RH}\end{array}$ \\
\hline $\mathrm{SF} 6, \mathrm{CO}_{2}$ & $\begin{array}{l}\text { Thermo } \\
\text { Electron } \\
\text { Corporation, } \\
\text { MIRAN } \\
\text { SapphIRe }\end{array}$ & $\begin{array}{l}\text { Ceiling } \\
\text { Supply } \\
\text { Return } \\
\text { Outside }\end{array}$ & $\begin{array}{l}\text { CO2: }+/-15 \% \\
\text { SF6: } 10 \% \text { up to } 1.0 \mathrm{ppm} \text {, } \\
20 \% \text { from } 1.0 \mathrm{ppm} \text { to } 4.0 \\
\text { ppm }\end{array}$ & $\begin{array}{l}\text { CO2: } 1 \mathrm{ppm} \\
\text { SF6: } 0.01 \mathrm{ppm}\end{array}$ & $\begin{array}{l}\text { CO2: } 0 \text { to } 1000 \mathrm{ppm} \\
\text { SF6: } 0 \text { to } 4 \mathrm{ppm}\end{array}$ \\
\hline $\mathrm{CO} 2$ & $\begin{array}{l}\text { Fuji Electric } \\
\text { Co., Infrared } \\
\mathrm{CO}_{2} \text { Controller } \\
\text { (Type ZFP9) }\end{array}$ & $\begin{array}{l}\text { Ceiling } \\
\text { Supply } \\
\text { Return } \\
\text { Outside }\end{array}$ & $+/-1 \%$ & $10 \mathrm{ppm}$ & 0 to $3000 \mathrm{ppm}$ \\
\hline Sound & $\begin{array}{l}\text { Brüel \& Kjær, } \\
2260 \text { Observer }\end{array}$ & & $+/-1 \%$ & $0.1 \mathrm{db}$ & $80 \mathrm{~dB}(10 \mathrm{db}$ to $90 \mathrm{~dB})$ \\
\hline
\end{tabular}


Classroom HVAC: Improving and Saving Energy (IVSE) Laboratory Study

Table 2. Measured temperature in the LBNL relocatable classroom test bed during HVAC operation days (continued on next page).

\begin{tabular}{|c|c|c|c|c|c|c|c|c|c|c|c|c|c|c|c|c|c|}
\hline \multirow[t]{2}{*}{ Date } & \multicolumn{3}{|c|}{ T_room $\left({ }^{\circ} \mathrm{F}\right)$} & \multicolumn{3}{|c|}{ T_out $\left({ }^{\circ} \mathrm{F}\right)$} & \multicolumn{3}{|c|}{ T_supply $\left({ }^{\circ} \mathrm{F}\right)$} & \multicolumn{3}{|c|}{$\mathrm{T}_{\text {_return }}\left({ }^{\circ} \mathrm{F}\right)$} & \multicolumn{3}{|c|}{ Tin - Tout $\left({ }^{\circ} \mathrm{F}\right)$} & \multirow[t]{2}{*}{ HVAC mode } & \multirow{2}{*}{$\begin{array}{l}\text { HVAC } \\
\text { System }\end{array}$} \\
\hline & $\begin{array}{c}\text { Avg } \\
\text { (Stdev) }\end{array}$ & Min & Max & Avg (Stdev) & Min & Max & $\begin{array}{c}\text { Avg } \\
\text { (Stdev) }\end{array}$ & Min & Max & $\begin{array}{c}\text { Avg } \\
\text { (Stdev) }\end{array}$ & Min & Max & $\begin{array}{c}\text { Avg } \\
(\text { Stdev })\end{array}$ & Min & Max & & \\
\hline 09/14/04 & $71.6(5.2)$ & 62.4 & 78.3 & $75.2(12.2)$ & 57.9 & 90.8 & $69.3(6.0)$ & 56.6 & 77.6 & $71.0(5.1)$ & 62.3 & 77.1 & $-3.6(7.5)$ & -16.2 & 6.9 & cool & $10 \mathrm{SEER}$ \\
\hline 09/15/04 & $74.7(2.8)$ & 68.5 & 78.4 & $80.1(11.1)$ & 64.2 & 93.5 & $70.6(6.1)$ & 55.8 & 78.7 & $74.0(2.7)$ & 68.5 & 77.5 & $-5.4(9.1)$ & -18.3 & 6.9 & cool & 10 SEER \\
\hline $09 / 27 / 04$ & $72.8(1.7)$ & 69.1 & 77.3 & $61.0(5.9)$ & 53.8 & 72.4 & $68.1(5.0)$ & 54.3 & 87.9 & $72.7(1.5)$ & 69.6 & 76.3 & $11.8(5.0)$ & 0.6 & 20.3 & mixed & IHPAC \\
\hline $09 / 28 / 04$ & $73.5(1.5)$ & 70.7 & 76.1 & $66.0(5.1)$ & 57.6 & 74.3 & $68.5(2.8)$ & 61.1 & 88.7 & $73.4(1.5)$ & 70.8 & 76.4 & $7.5(4.0)$ & -0.5 & 16.9 & & IHPAC \\
\hline $09 / 29 / 04$ & $72.0(1.0)$ & 69.9 & 74.4 & $61.1(3.2)$ & 56.7 & 67.5 & $67.2(3.9)$ & 63.7 & 87.0 & $71.6(1.0)$ & 68.0 & 74.1 & $10.9(3.1)$ & 3.5 & 17.0 & mixed & IHPAC \\
\hline $09 / 30 / 04$ & $72.2(1.1)$ & 70.1 & 75.0 & $60.8(3.8)$ & 55.9 & 69.0 & $67.4(3.7)$ & 63.1 & 86.8 & $71.8(1.2)$ & 68.3 & 74.3 & $11.4(3.5)$ & 3.0 & 18.0 & & IHPAC \\
\hline $10 / 02 / 04$ & $73.2(1.7)$ & 69.9 & 77.5 & $63.7(6.9)$ & 54.0 & 74.2 & $68.0(4.4)$ & 54.6 & 91.7 & $72.6(1.4)$ & 69.7 & 75.7 & $9.5(5.7)$ & -0.2 & 19.9 & mixed & IHPAC \\
\hline $10 / 03 / 04$ & 72.5 (1.4) & 69.8 & 75.8 & $60.6(6.4)$ & 52.9 & 72.8 & $67.6(5.1)$ & 62.0 & 90.6 & $72.0(1.3)$ & 67.7 & 75.0 & $11.9(5.8)$ & 1.5 & 21.4 & heat & IHPAC \\
\hline $10 / 04 / 04$ & $71.9(1.0)$ & 69.7 & 75.0 & $60.9(4.0)$ & 56.1 & 75.2 & $67.2(4.0)$ & 63.7 & 89.8 & $71.6(1.1)$ & 67.9 & 75.0 & $11.0(3.8)$ & -3.4 & 18.0 & & IHPAC \\
\hline $10 / 05 / 04$ & $72.3(1.3)$ & 69.7 & 75.5 & $63.0(7.2)$ & 54.6 & 77.3 & $67.6(4.5)$ & 63.1 & 91.8 & $72.0(1.1)$ & 69.5 & 75.5 & $9.3(6.5)$ & -4.7 & 19.2 & heat & IHPAC \\
\hline $10 / 06 / 04$ & $73.9(2.2)$ & 69.8 & 78.7 & $71.7(10.8)$ & 56.3 & 88.4 & $69.3(5.0)$ & 54.3 & 91.5 & $73.4(1.7)$ & 70.3 & 77.2 & $2.2(9.0)$ & -12.9 & 17.3 & mixed & IHPAC \\
\hline $10 / 07 / 04$ & 73.5 (1.9) & 70.5 & 78.0 & $68.5(7.9)$ & 58.1 & 82.9 & $68.1(3.4)$ & 55.0 & 78.7 & $73.0(1.5)$ & 71.0 & 76.3 & $5.0(6.3)$ & -6.9 & 12.9 & cool & IHPAC \\
\hline $10 / 08 / 04$ & $73.7(2.0)$ & 70.1 & 78.2 & $69.2(9.4)$ & 56.7 & 86.3 & $68.8(4.3)$ & 55.8 & 91.4 & $73.1(1.6)$ & 70.6 & 76.5 & $4.5(7.8)$ & -10.2 & 17.3 & mixed & IHPAC \\
\hline $10 / 09 / 04$ & 73.3 (1.9) & 69.8 & 77.3 & $64.9(8.4)$ & 54.7 & 81.9 & $68.5(3.8)$ & 54.6 & 87.2 & $72.9(1.5)$ & 70.4 & 76.0 & $8.4(6.8)$ & -6.2 & 19.0 & $\mathrm{mi}>$ & IHPAC \\
\hline $10 / 10 / 04$ & $73.7(2.1)$ & 69.8 & 77.8 & $68.7(10.1)$ & 55.2 & 85.5 & $69.3(4.5)$ & 54.7 & 90.5 & $73.2(1.6)$ & 70.2 & 76.3 & $05.0(8.5)$ & -9.8 & 18.7 & mixed & IHPAC \\
\hline & $75.2(1.8)$ & 71.5 & 79.5 & & 61.8 & 90.6 & $70.3(5.7)$ & 52.7 & & $74.6(1.5)$ & 71.9 & 79.2 & $-01.4(8.5)$ & -15.0 & 9.9 & & IHPAC \\
\hline $10 / 12 / 04$ & $75.6(1.3)$ & 72.7 & 79.8 & $79.9(9.9)$ & 67.5 & 96.7 & $68.3(6.9)$ & 51.2 & 79.7 & $75.0(1.1)$ & 72.2 & 78.8 & $-04.3(9.4)$ & -20.5 & 9.0 & cool & IHPAC \\
\hline $10 / 13 / 04$ & $75.7(1.5)$ & 72.7 & 80.0 & $78.7(10.6)$ & 65.6 & 94.7 & $69.0(6.9)$ & 49.3 & 80.4 & $75.1(1.2)$ & 72.1 & 80.0 & $-3.0(10.3)$ & -19.0 & 13.1 & cool & IHPAC \\
\hline $10 / 14 / 04$ & $75.5(1.3)$ & 72.0 & 79.5 & $75.8(8.7)$ & 62.0 & 89.2 & $68.8(6.3)$ & 50.6 & 80.5 & $74.9(0.9)$ & 71.9 & 78.1 & $-00.2(8.5)$ & -14.1 & 13.9 & & IHPAC \\
\hline $10 / 15 / 04$ & $73.9(1.7)$ & 71.5 & 77.7 & $66.4(7.9)$ & 55.1 & 84.0 & $67.8(3.6)$ & 53.6 & 78.0 & $73.4(1.2)$ & 70.4 & 76.4 & $07.5(6.7)$ & -8.3 & 17.3 & mixed & IHPAC \\
\hline $10 / 16 / 04$ & $72.5(1.2)$ & 70.1 & 74.9 & $62.9(3.2)$ & 57.8 & 68.6 & $67.7(3.1)$ & 64.1 & 88.6 & $72.1(1.3)$ & 68.9 & 74.6 & $09.6(2.5)$ & 3.3 & 15.9 & heat & IHPAC \\
\hline $10 / 17 / 04$ & $73.5(0.9)$ & 71.0 & 75.4 & $62.8(1.7)$ & 59.8 & 67.4 & $68.3(2.0)$ & 65.9 & 74.8 & $73.0(1.4)$ & 68.5 & 74.7 & $10.7(1.7)$ & 6.1 & 13.4 & none & IHPAC \\
\hline $10 / 18 / 04$ & $72.3(1.2)$ & 70.1 & 75.0 & $63.3(5.6)$ & 54.7 & 73.3 & $67.5(4.8)$ & 62.8 & 89.6 & $71.7(1.2)$ & 67.7 & 74.4 & $08.9(5.2)$ & -1.5 & 19.0 & heat & IHPAC \\
\hline $10 / 19 / 04$ & $75.0(3.0)$ & 68.8 & 79.6 & $57.1(3.4)$ & 52.8 & 62.9 & $73.1(3.2)$ & 64.5 & 78.8 & $71.5(3.6)$ & 65.1 & 77.2 & $17.9(3.4)$ & 9.2 & 22.8 & heat & IHPAC \\
\hline $10 / 20 / 04$ & $72.0(1.2)$ & 69.7 & 75.0 & $57.5(6.0)$ & 49.4 & 69.4 & $68.0(6.8)$ & 60.2 & 90.8 & $71.3(1.3)$ & 67.1 & 75.0 & $14.5(6.0)$ & 2.4 & 24.3 & heat & IHPAC \\
\hline $10 / 21 / 04$ & $72.3(1.6)$ & 69.3 & 76.8 & $55.7(6.3)$ & 48.9 & 71.2 & $70.0(7.6)$ & 59.4 & 90.8 & $71.0(1.8)$ & 65.2 & 75.1 & $16.7(5.9)$ & 1.7 & 25.2 & heat & IHPAC \\
\hline
\end{tabular}


Classroom HVAC: Improving and Saving Energy (IVSE) Laboratory Study

Table 2 (continued) Measured temperature in the LBNL relocatable classroom test bed during HVAC operation days.

\begin{tabular}{|c|c|c|c|c|c|c|c|c|c|c|c|c|c|c|c|c|c|}
\hline \multirow[t]{2}{*}{ Date } & \multicolumn{3}{|c|}{$\mathrm{T}_{-}$room $\left({ }^{\circ} \mathrm{F}\right)$} & \multicolumn{3}{|c|}{$\mathrm{T}_{-}$out $\left({ }^{\circ} \mathrm{F}\right)$} & \multicolumn{3}{|c|}{$\mathrm{T}_{\text {_supply }}\left({ }^{\circ} \mathrm{F}\right)$} & \multicolumn{3}{|c|}{$\mathrm{T}_{\text {_return }}\left({ }^{\circ} \mathrm{F}\right)$} & \multicolumn{3}{|c|}{ Tin - Tout $\left({ }^{\circ} \mathrm{F}\right)$} & \multirow[t]{2}{*}{ HVAC mode } & \multirow{2}{*}{$\begin{array}{l}\text { HVAC } \\
\text { System }\end{array}$} \\
\hline & $\begin{array}{c}\text { Avg } \\
\text { (Stdev) }\end{array}$ & Min & Max & Avg (Stdev) & Min & Max & $\begin{array}{c}\text { Avg } \\
\text { (Stdev) }\end{array}$ & Min & Max & $\begin{array}{c}\text { Avg } \\
\text { (Stdev) }\end{array}$ & Min & Max & $\begin{array}{c}\text { Avg } \\
\text { (Stdev) }\end{array}$ & Min & Max & & \\
\hline $10 / 22 / 04$ & $72.2(1.1)$ & 69.9 & 74.9 & $61.0(4.5)$ & 54.2 & 72.5 & $67.5(5.0)$ & 62.3 & 90.8 & $71.6(1.1)$ & 68.5 & 76.0 & $11.3(4.3)$ & 1.1 & 19.3 & heat & IHPAC \\
\hline $10 / 23 / 04$ & $71.7(1.1)$ & 69.6 & 75.1 & $56.5(1.0)$ & 55.0 & 59.3 & $7.6(5.8)$ & 62.8 & 91.7 & $71.5(1.1)$ & 70.0 & 75.6 & $15.2(1.5)$ & 10.7 & 19.5 & heat & IHPAC \\
\hline $10 / 24 / 04$ & $72.0(1.1)$ & 69.7 & 74.9 & $60.7(4.5)$ & 53.7 & 69.4 & $67.9(5.2)$ & 62.5 & 92.9 & $71.8(1.0)$ & 69.9 & 75.7 & $11.3(4.7)$ & 2.9 & 20.8 & heat & IHPAC \\
\hline $10 / 25 / 04$ & $71.9(1.2)$ & 69.2 & 74.9 & $59.2(5.6)$ & 51.5 & 69.6 & $68.0(6.5)$ & 61.2 & 92.6 & $71.6(1.1)$ & 69.4 & 76.4 & $12.7(5.6)$ & 3.3 & 22.5 & heat & IHPAC \\
\hline $10 / 26 / 04$ & $72.0(1.3)$ & 69.2 & 75.3 & $55.9(5.5)$ & 49.6 & 67.6 & $8.4(7.6)$ & 59.3 & 92.2 & $71.6(1.3)$ & 69.4 & 75.8 & $16.1(5.8)$ & 3.6 & 25.0 & heat & IHPAC \\
\hline $10 / 27 / 04$ & $71.9(1.4)$ & 68.6 & 75.0 & $52.1(4.2)$ & 47.0 & 60.4 & $69.2(8.3)$ & 58.6 & 92.2 & $71.6(1.3)$ & 69.0 & 75.8 & $19.9(4.5)$ & 10.5 & 27.3 & heat & IHPAC \\
\hline $10 / 28 / 04$ & $71.9(1.3)$ & 68.8 & 75.2 & $56.0(4.7)$ & 48.5 & 62.9 & $8.5(7.4)$ & 59.6 & 93.8 & $71.7(1.3)$ & 68.9 & 76.1 & $15.9(4.9)$ & 8.1 & 25.5 & heat & $\mathrm{AC}$ \\
\hline $10 / 29 / 04$ & $72.6(2.9)$ & 66.2 & 88.2 & $59.5(4.6)$ & 52.1 & 68.6 & $68.8(9.2)$ & 43.9 & 107.9 & $72.1(3.1)$ & 66.0 & 90.1 & $13.1(4.8)$ & 3.1 & 22.4 & mixed & IHPAC \\
\hline $10 / 30 / 04$ & $69.9(1.3)$ & 67.2 & 73.6 & $56.7(4.2)$ & 50.1 & 65.2 & $65.9(6.5)$ & 60.6 & 93.1 & $69.7(1.4)$ & 67.4 & 75.9 & $13.2(4.5)$ & 4.2 & 22.8 & heat & IHPAC \\
\hline $10 / 31 / 04$ & $70.3(1.2)$ & 67.7 & 74.4 & $58.0(6.1)$ & 50.2 & 68.9 & $66.8(5.5)$ & 59.8 & 90.9 & $70.1(1.2)$ & 67.7 & 74.2 & $12.3(5.8)$ & 3.1 & 23.3 & at & $\mathrm{AC}$ \\
\hline $11 / 01 / 04$ & $71.1(1.4)$ & 67.9 & 74.0 & $60.4(6.1)$ & 51.5 & 72.6 & $67.7(5.0)$ & 60.6 & 91.6 & $70.7(1.4)$ & 67.5 & 74.3 & $51.2(9.4)$ & 33.4 & 69.6 & heat & IHPAC \\
\hline $11 / 02 / 04$ & $71.4(1.6)$ & 68.2 & 74.9 & $60.9(5.9)$ & 51.1 & 70.9 & $66.8(4.6)$ & 48.3 & 89.1 & $70.8(1.5)$ & 68.3 & 73.5 & $51.0(8.8)$ & 33.1 & 3.7 & mixed. & $\mathrm{AC}$ \\
\hline $11 / 03 / 04$ & $69.8(1.4)$ & 65.7 & 74.0 & $54.2(2.8)$ & 48.6 & 59.9 & $65.0(5.7)$ & 58.0 & 89.6 & $69.5(1.3)$ & 66.2 & 74.7 & $60.3(5.2)$ & 47.4 & 71.5 & heat & IHPAC \\
\hline $11 / 04 / 04$ & $70.0(1.5)$ & 66.9 & 74.4 & $52.4(3.0)$ & 46.7 & 57.0 & $66.4(8.0)$ & 57.4 & 90.4 & $69.0(2.2)$ & 62.1 & 74.1 & $63.6(5.9)$ & 52.5 & 77.9 & heat & IHPAC \\
\hline $11 / 05 / 04$ & $70.1(1.4)$ & 67.0 & 73.8 & $56.6(4.6)$ & 48.3 & 64.1 & $66.2(6.1)$ & 59.7 & 91.4 & $69.7(1.4)$ & 66.2 & 74.7 & 56.2 & 44.0 & 75.9 & heat & IHPAC \\
\hline $11 / 06 / 04$ & $70.3(1.3)$ & 67.2 & 74.1 & $55.9(4.3)$ & 48.6 & 65.1 & $66.1(6.4)$ & 59.5 & 93.0 & $69.6(1.5)$ & 66.8 & 75.8 & $57.8(8.0)$ & 39.2 & 76.6 & mixed. & IHPAC \\
\hline $11 / 07 / 04$ & $70.2(1.2)$ & 67.4 & 73.9 & $56.0(2.8)$ & 50.9 & 61.2 & $65.4(5.7)$ & 60.2 & 92.1 & $69.5(1.6)$ & 65.2 & 75.9 & $57.4(5.6)$ & 45.3 & 72.6 & he & IHPAC \\
\hline 03/01/05 & 71.9 (1.7) & 67.1 & 74.1 & $59.9(5.6)$ & 50.1 & 67.7 & $67.8(7.3)$ & 59.9 & 90.9 & $72.0(1.9)$ & 66.9 & 74.5 & $12.0(5.9)$ & 2.2 & 22.0 & heat & 10 SEER \\
\hline $03 / 02 / 05$ & $71.0(1.4)$ & 67.3 & 72.7 & $57.8(4.3)$ & 51.3 & 65.2 & $67.8(7.4)$ & 60.6 & 92.0 & $72.0(2.0)$ & 66.8 & 74.2 & $13.2(4.6)$ & 3.5 & 19.4 & heat & 10 SEER \\
\hline $03 / 03 / 05$ & 71.9 (1.6) & 66.2 & 74.5 & $3(5.6)$ & 47.9 & 69.8 & $68.2(7.4)$ & 57.7 & 90.7 & $72.1(1.8)$ & 66 & 74.5 & $12.7(5.8)$ & 0.0 & 24.5 & heat & 10 SEER \\
\hline $03 / 04 / 05$ & $71.9(1.8)$ & 67.1 & 74.6 & $54.3(3.4)$ & 50.5 & 62.4 & $67.9(8.0)$ & 60.4 & 91.4 & $72.1(2.0)$ & 66.9 & 74.7 & $17.6(4.7)$ & 6.2 & 23.2 & heat & 10 SEER \\
\hline $03 / 05 / 05$ & $72.2(1.3)$ & 68.8 & 74.2 & $61.6(8.3)$ & 48.3 & 73.3 & $67.9(6.4)$ & 58.6 & 90.0 & $72.3(1.5)$ & 69.0 & 74.3 & $10.6(8.2)$ & -1.4 & 23.8 & heat & 10 SEER \\
\hline $03 / 06 / 05$ & $72.9(1.0)$ & 69.9 & 75.3 & $64.7(8.7)$ & 51.4 & 76.3 & $68.7(5.8)$ & 60.8 & 91.1 & $73.0(1.2)$ & 70.0 & 75.8 & $08.2(8.3)$ & -3.5 & 21.5 & heat & 10 SEER \\
\hline 03/07/05 & $72.6(1.1)$ & 70.1 & 75.0 & $63.5(7.0)$ & 51.9 & 73.6 & $68.1(6.0)$ & 61.4 & 92.4 & $72.7(1.3)$ & 70.0 & 75.0 & $3.9(15.0)$ & -32.4 & 34.4 & heat & 10 SEER \\
\hline $03 / 08 / 05$ & $72.5(1.0)$ & 66.2 & 74.4 & $65.3(8.7)$ & 52.0 & 76.9 & $70.0(6.8)$ & 58.9 & 92.3 & $72.4(0.9)$ & 66.2 & 74.1 & $4.0(17.5)$ & -23.3 & 37.4 & heat & 10 SEER \\
\hline 03/09/05 & $75.1(3.2)$ & 67.0 & 80.4 & $67.2(10.1)$ & 52.6 & 80.7 & $71.8(5.6)$ & 57.5 & 90.2 & 74.7 (2.9) & 67.0 & 79.4 & $2.6(20.9)$ & -29.9 & 30.0 & mixed & 10 SEER \\
\hline $03 / 10 / 05$ & 76.9 (2.6) & 71.5 & 81.9 & $73.6(10.2)$ & 57.6 & 86.7 & $71.2(6.1)$ & 58.1 & 83.8 & $76.5(2.5)$ & 71.1 & 81.3 & $-25.9(16.2)$ & -49.5 & 8.1 & Cool & 10 SEER \\
\hline $03 / 11 / 05$ & $78.0(2.2)$ & 74.2 & 83.1 & $76.5(10.4)$ & 60.2 & 88.6 & $72.2(7.0)$ & 56.3 & 86.5 & $77.3(2.1)$ & 74.1 & 82.6 & $-32.3(20.9)$ & -62.0 & 8.9 & Cool & 10 SEER \\
\hline $03 / 12 / 05$ & $76.4(1.4)$ & 73.2 & 78.6 & $58.7(2.1)$ & 55.3 & 61.4 & $69.7(5.3)$ & 55.0 & 76.1 & $76.0(1.3)$ & 73.0 & 77.9 & $20.2(7.8)$ & 7.9 & 40.0 & Cool & 10 SEER \\
\hline 03/13/05 & $76.5(2.6)$ & 70.2 & 79.4 & $63.7(6.3)$ & 54.5 & 73.2 & $70.6(6.2)$ & 54.8 & 82.7 & $75.9(2.5)$ & 70.0 & 79.0 & $-2.8(18.6)$ & -35.5 & 26.2 & Cool & 10 SEER \\
\hline
\end{tabular}


Classroom HVAC: Improving and Saving Energy (IVSE) Laboratory Study

Table 3. Measured relative humidities in the LBNL relocatable classroom test bed during HVAC operation days (continued on next page).

\begin{tabular}{|c|c|c|c|c|c|c|c|c|c|c|c|}
\hline \multirow[t]{2}{*}{ Date } & \multicolumn{3}{|c|}{ RH_room } & \multicolumn{3}{|c|}{ RH_out } & \multicolumn{3}{|c|}{ RHsupply } & \multirow[t]{2}{*}{ HVAC mode } & \multirow{2}{*}{$\begin{array}{c}\text { HVAC } \\
\text { Type }\end{array}$} \\
\hline & $\begin{array}{c}\text { Avg } \\
\text { (Stdev) }\end{array}$ & Min & Max & Avg (Stdev) & Min & Max & Avg (Stdev) & Min & Max & & \\
\hline $09 / 14 / 04$ & $51.0(8.0)$ & 39.5 & 64.4 & $49.6(21.2)$ & 25.1 & 82.4 & $59.1(10.6)$ & 40.1 & 79.7 & cool & 10 SEER \\
\hline $09 / 15 / 04$ & $42.6(1.9)$ & 39.0 & 46.9 & $38.7(11.0)$ & 24.0 & 54.4 & $53.9(12.1)$ & 38.9 & 88.2 & cool & 10 SEER \\
\hline $09 / 27 / 04$ & $49.0(1.8)$ & 44.1 & 53.0 & $79.6(14.2)$ & 54.9 & 97.7 & $63.1(8.8)$ & 34.7 & 98.2 & mixed & IHPAC \\
\hline $09 / 28 / 04$ & $49.4(3.6)$ & 43.9 & 55.6 & $69.7(15.6)$ & 47.4 & 94.9 & $63.2(6.5)$ & 35.3 & 74.3 & mixed & IHPAC \\
\hline 09/29/04 & $49.5(1.5)$ & 46.5 & 53.1 & $79.2(7.0)$ & 64.7 & 88.8 & $63.7(6.6)$ & 38.3 & 69.3 & mixed & IHPAC \\
\hline 09/30/04 & $47.4(1.5)$ & 44.2 & 50.8 & $74.0(11.8)$ & 51.2 & 89.3 & $60.5(5.9)$ & 34.7 & 68.8 & heat & IHPAC \\
\hline $10 / 02 / 04$ & $46.9(1.7)$ & 42.7 & 51.0 & $70.4(18.0)$ & 47.7 & 96.3 & $61.2(7.5)$ & 30.7 & 88.9 & mixed & IHPAC \\
\hline $10 / 03 / 04$ & $48.0(1.6)$ & 45.0 & 52.0 & $80.4(16.6)$ & 53.6 & 99.6 & $62.3(8.3)$ & 31.7 & 71.2 & heat & IHPAC \\
\hline $10 / 04 / 04$ & $51.3(1.3)$ & 48.1 & 54.8 & $83.6(10.5)$ & 53.4 & 95.6 & $66.3(7.2)$ & 33.3 & 73.5 & heat & IHPAC \\
\hline $10 / 05 / 04$ & $51.0(1.5)$ & 47.8 & 54.8 & $80.2(18.3)$ & 49.4 & 100.5 & $65.5(7.7)$ & 34.0 & 74.5 & heat & IHPAC \\
\hline $10 / 06 / 04$ & $48.3(1.8)$ & 44.0 & 52.6 & $59.8(16.9)$ & 35.8 & 83.1 & $62.2(10.2)$ & 30.6 & 99.3 & mixed & IHPAC \\
\hline $10 / 07 / 04$ & $52.0(3.3)$ & 45.8 & 57.7 & $71.1(20.7)$ & 40.6 & 100.2 & $68.1(7.0)$ & 48.8 & 96.1 & cool & IHPAC \\
\hline $10 / 08 / 04$ & $51.0(2.1)$ & 45.1 & 56.0 & $68.9(19.2)$ & 37.8 & 94.1 & $66.4(8.5)$ & 32.1 & 98.6 & mixed & IHPAC \\
\hline $10 / 09 / 04$ & $43.2(5.0)$ & 37.0 & 53.5 & $63.2(21.3)$ & 33.6 & 94.9 & $54.3(7.6)$ & 34.2 & 70.3 & mixed & IHPAC \\
\hline $10 / 10 / 04$ & $35.1(1.9)$ & 30.9 & 38.8 & $45.5(13.4)$ & 25.3 & 64.8 & $43.5(5.7)$ & 23.5 & 63.0 & mixed & IHPAC \\
\hline $10 / 11 / 04$ & $22.3(3.1)$ & 19.3 & 30.8 & $21.8(6.5)$ & 13.3 & 34.3 & $26.6(4.2)$ & 19.9 & 40.4 & cool & IHPAC \\
\hline $10 / 12 / 04$ & $29.9(2.2)$ & 25.7 & 34.3 & $27.9(8.0)$ & 16.9 & 42.5 & $41.6(9.6)$ & 26.3 & 76.7 & cool & IHPAC \\
\hline $10 / 13 / 04$ & $29.8(3.1)$ & 23.7 & 37.4 & $28.8(6.8)$ & 17.7 & 41.1 & $40.8(10.9)$ & 27.8 & 79.6 & cool & IHPAC \\
\hline $10 / 14 / 04$ & $39.3(4.3)$ & 29.6 & 47.0 & $42.7(8.8)$ & 29.6 & 63.6 & $55.4(13.7)$ & 35.4 & 100.9 & cool & IHPAC \\
\hline $10 / 15 / 04$ & 46.7 (1.7) & 43.0 & 51.1 & $70.3(17.4)$ & 37.6 & 94.9 & $63.3(7.9)$ & 46.6 & 94.7 & mixed & IHPAC \\
\hline $10 / 16 / 04$ & $47.1(1.4)$ & 44.7 & 50.6 & $74.0(6.3)$ & 63.0 & 84.0 & $60.7(5.0)$ & 32.5 & 66.0 & heat & IHPAC \\
\hline $10 / 17 / 04$ & $52.1(2.9)$ & 45.5 & 58.6 & $86.9(5.8)$ & 76.7 & 95.0 & $68.8(7.3)$ & 47.3 & 76.2 & none & IHPAC \\
\hline $10 / 18 / 04$ & $48.0(2.7)$ & 42.8 & 54.1 & $74.5(18.1)$ & 47.6 & 98.2 & $61.5(8.8)$ & 34.9 & 74.1 & heat & IHPAC \\
\hline $10 / 19 / 04$ & $44.1(4.9)$ & 37.5 & 56.4 & $95.5(2.6)$ & 87.8 & 99.6 & $51.5(9.2)$ & 41.8 & 78.2 & heat & IHPAC \\
\hline $10 / 20 / 04$ & $43.8(1.6)$ & 40.9 & 47.5 & $79.4(19.3)$ & 43.7 & 99.9 & $55.1(10.0)$ & 30.0 & 69.8 & heat & IHPAC \\
\hline $10 / 21 / 04$ & $38.1(1.2)$ & 35.5 & 41.3 & $73.0(14.0)$ & 43.0 & 86.5 & $45.5(9.1)$ & 25.2 & 60.1 & heat & IHPAC \\
\hline
\end{tabular}


Classroom HVAC: Improving and Saving Energy (IVSE) Laboratory Study

Table 3 (continued). Measured relative humidities in the LBNL relocatable classroom test bed during HVAC operation days

\begin{tabular}{|c|c|c|c|c|c|c|c|c|c|c|c|}
\hline \multirow[t]{2}{*}{ Date } & \multicolumn{3}{|c|}{ RH_room } & \multicolumn{3}{|c|}{ RH_out } & \multicolumn{3}{|c|}{ RHsupply } & \multirow[t]{2}{*}{ HVAC mode } & \multirow{2}{*}{$\begin{array}{c}\text { HVAC } \\
\text { Type }\end{array}$} \\
\hline & $\begin{array}{c}\text { Avg } \\
\text { (Stdev) }\end{array}$ & Min & Max & Avg (Stdev) & Min & Max & Avg (Stdev) & Min & Max & & \\
\hline $10 / 22 / 04$ & $45.9(1.4)$ & 42.6 & 49.3 & $74.0(12.6)$ & 48.4 & 91.6 & $59.4(7.7)$ & 29.8 & 69.1 & heat & IHPAC \\
\hline $10 / 23 / 04$ & $49.8(3.4)$ & 42.6 & 58.4 & $90.9(4.5)$ & 82.0 & 97.7 & $63.6(10.2)$ & 31.5 & 77.9 & heat & IHPAC \\
\hline $10 / 24 / 04$ & $48.1(1.8)$ & 44.3 & 52.7 & $78.1(13.7)$ & 55.4 & 98.1 & $60.6(8.1)$ & 31.8 & 72.4 & heat & IHPAC \\
\hline $10 / 25 / 04$ & $44.2(1.5)$ & 41.1 & 48.1 & $73.7(14.3)$ & 48.3 & 94.9 & $55.1(8.9)$ & 27.1 & 66.2 & heat & IHPAC \\
\hline $10 / 26 / 04$ & $41.5(2.8)$ & 36.6 & 49.4 & $78.1(18.3)$ & 46.8 & 101.8 & $50.5(9.8)$ & 27.9 & 69.1 & heat & IHPAC \\
\hline $10 / 27 / 04$ & $36.6(1.8)$ & 33.6 & 42.3 & $77.2(13.0)$ & 54.8 & 95.6 & $43.5(8.9)$ & 24.7 & 59.7 & heat & IHPAC \\
\hline $10 / 28 / 04$ & $41.6(1.6)$ & 38.2 & 45.4 & $78.8(11.2)$ & 63.5 & 97.5 & $51.3(9.8)$ & 24.4 & 63.9 & heat & IHPAC \\
\hline $10 / 29 / 04$ & $41.7(3.2)$ & 28.0 & 46.6 & $70.3(15.4)$ & 46.3 & 91.7 & $52.4(12.1)$ & 16.2 & 102.4 & mixed & IHPAC \\
\hline $10 / 30 / 04$ & $48.5(2.7)$ & 40.3 & 53.2 & $85.0(10.1)$ & 64.3 & 97.4 & $61.9(11.1)$ & 24.4 & 72.0 & heat & IHPAC \\
\hline $10 / 31 / 04$ & $38.3(7.0)$ & 27.2 & 51.6 & $61.1(24.8)$ & 25.6 & 98.3 & $45.5(11.6)$ & 25.8 & 69.5 & heat & IHPAC \\
\hline $11 / 01 / 04$ & $24.2(1.1)$ & 21.6 & 26.3 & $34.4(5.8)$ & 23.0 & 46.1 & $28.1(3.2)$ & 15.9 & 33.9 & heat & IHPAC \\
\hline $11 / 02 / 04$ & $36.3(3.7)$ & 29.3 & 45.2 & $56.7(5.3)$ & 43.9 & 64.5 & $46.7(8.5)$ & 20.9 & 97.2 & mixed & IHPAC \\
\hline $11 / 03 / 04$ & $40.3(3.5)$ & 35.3 & 50.0 & $71.7(8.4)$ & 56.8 & 91.6 & $51.0(7.0)$ & 26.2 & 62.3 & heat & IHPAC \\
\hline $11 / 04 / 04$ & $40.1(1.6)$ & 36.0 & 44.4 & $79.0(7.0)$ & 67.3 & 94.0 & $50.0(10.8)$ & 25.1 & 65.3 & heat & IHPAC \\
\hline $11 / 05 / 04$ & $39.6(1.7)$ & 36.0 & 42.7 & $67.6(10.6)$ & 51.4 & 85.7 & $49.3(7.8)$ & 23.1 & 59.3 & heat & IHPAC \\
\hline $11 / 06 / 04$ & $46.4(3.2)$ & 37.7 & 52.4 & $84.0(9.6)$ & 61.6 & 97.6 & $59.7(11.1)$ & 23.4 & 70.6 & mixed & IHPAC \\
\hline $11 / 07 / 04$ & $46.0(1.7)$ & 41.5 & 50.5 & $80.1(6.6)$ & 66.6 & 92.5 & $59.1(8.7)$ & 27.1 & 66.8 & heat & IHPAC \\
\hline $03 / 01 / 05$ & $41.6(1.0)$ & 38.4 & 43.9 & $66.5(14.9)$ & 45.4 & 90.1 & 50.7 (8.6) & 25.1 & 62.6 & heat & 10 SEER \\
\hline $03 / 02 / 05$ & $43.7(2.6)$ & 39.8 & 49.1 & $74.1(15.4)$ & 51.8 & 99.6 & $51.8(9.2)$ & 27.6 & 68.0 & heat & 10 SEER \\
\hline $03 / 03 / 05$ & $41.8(1.8)$ & 38.5 & 47.4 & $68.8(12.8)$ & 48.6 & 92.7 & $50.6(9.3)$ & 24.3 & 62.4 & heat & 10 SEER \\
\hline $03 / 04 / 05$ & $46.9(2.7)$ & 43.5 & 54.6 & $91.5(8.6)$ & 69.3 & 99.5 & $57.7(11.7)$ & 27.4 & 71.5 & heat & 10 SEER \\
\hline $03 / 05 / 05$ & $46.7(2.8)$ & 41.5 & 53.5 & $75.2(18.1)$ & 47.1 & 100.2 & $58.3(10.1)$ & 26.6 & 69.0 & heat & 10 SEER \\
\hline $03 / 06 / 05$ & $46.3(2.4)$ & 41.6 & 50.4 & $68.0(19.4)$ & 42.7 & 94.6 & $57.0(9.6)$ & 27.4 & 69.7 & heat & 10 SEER \\
\hline 03/07/05 & $48.2(2.6)$ & 44.9 & 55.1 & $72.0(15.0)$ & 50.5 & 96.5 & $60.1(9.6)$ & 28.0 & 69.0 & heat & 10 SEER \\
\hline $03 / 08 / 05$ & $52.0(3.4)$ & 45.7 & 57.7 & $74.1(17.2)$ & 52.2 & 97.4 & $61.4(11.1)$ & 26.7 & 71.3 & heat & 10 SEER \\
\hline 03/09/05 & $48.2(1.1)$ & 45.1 & 52.3 & $74.4(20.8)$ & 48.8 & 101.8 & $65.1(19.0)$ & 30.3 & 100.5 & mixed & 10 SEER \\
\hline 03/10/05 & $41.0(3.8)$ & 36.5 & 49.1 & $45.3(14.0)$ & 28.6 & 70.9 & $54.1(9.6)$ & 36.3 & 76.2 & Cool & 10 SEER \\
\hline $03 / 11 / 05$ & $36.5(4.7)$ & 30.9 & 44.2 & $39.9(18.0)$ & 22.4 & 71.3 & $47.6(11.0)$ & 29.3 & 77.3 & Cool & 10 SEER \\
\hline $03 / 12 / 05$ & $42.9(1.6)$ & 38.7 & 46.3 & $89.9(5.3)$ & 82.0 & 97.8 & $67.1(15.3)$ & 43.4 & 95.1 & Cool & 10 SEER \\
\hline $03 / 13 / 05$ & $41.6(2.7)$ & 38.5 & 48.2 & $67.8(16.4)$ & 44.7 & 93.9 & $59.8(13.4)$ & 32.8 & 87.0 & Cool & 10 SEER \\
\hline
\end{tabular}


Classroom HVAC: Improving and Saving Energy (IVSE) Laboratory Study

Table 4. School day $\mathrm{CO}_{2}$ concentrations measured in the center of the RC.

\begin{tabular}{|c|c|c|c|c|c|}
\hline Date & \multicolumn{3}{|c|}{$\mathrm{CO}_{2}$ Concentration (ppm) } & HVAC Mode & HVAC Type \\
\hline & Avg (Stdev) & Min & Max & & \\
\hline $9 / 15 / 05$ & $499(63)$ & 390 & 579 & cool & 10 SEER \\
\hline 9/28/04 & $486(71)$ & 390 & 595 & mixed & IHPAC \\
\hline $9 / 27 / 04$ & $527(89)$ & 390 & 727 & mixed & IHPAC \\
\hline $9 / 29 / 04$ & $493(73)$ & 390 & 607 & mixed & IHPAC \\
\hline $9 / 30 / 04$ & $481(69)$ & 377 & 578 & heat & IHPAC \\
\hline $10 / 2 / 04$ & $483(69)$ & 378 & 586 & mixed & IHPAC \\
\hline $10 / 3 / 04$ & $484(66)$ & 381 & 583 & heat & IHPAC \\
\hline $10 / 4 / 04$ & $488(69)$ & 393 & 593 & heat & IHPAC \\
\hline $10 / 5 / 04$ & $491(67)$ & 390 & 594 & heat & IHPAC \\
\hline $10 / 6 / 04$ & $505(76)$ & 389 & 606 & mixed & IHPAC \\
\hline $10 / 7 / 04$ & $490(71)$ & 380 & 595 & cool & IHPAC \\
\hline $10 / 8 / 04$ & $493(73)$ & 393 & 609 & mixed & IHPAC \\
\hline $10 / 9 / 04$ & 477 (67) & 379 & 577 & mixed & IHPAC \\
\hline $10 / 10 / 04$ & $480(69)$ & 378 & 577 & mixed & IHPAC \\
\hline $10 / 11 / 04$ & 391 (19) & 347 & 456 & cool & IHPAC \\
\hline $10 / 12 / 04$ & $429(35)$ & 375 & 538 & cool & IHPAC \\
\hline $10 / 13 / 04$ & $426(26)$ & 374 & 508 & cool & IHPAC \\
\hline $10 / 14 / 04$ & 485 (64) & 421 & 625 & cool & IHPAC \\
\hline $10 / 15 / 04$ & $505(62)$ & 397 & 600 & mixed & IHPAC \\
\hline $10 / 16 / 04$ & $478(66)$ & 382 & 572 & heat & IHPAC \\
\hline $10 / 17 / 04$ & $478(66)$ & 381 & 566 & none & IHPAC \\
\hline $10 / 18 / 04$ & $493(67)$ & 387 & 599 & heat & IHPAC \\
\hline $10 / 19 / 04$ & $1060(468)$ & 393 & 2177 & heat & IHPAC \\
\hline $10 / 20 / 04$ & $488(61)$ & 388 & 588 & heat & IHPAC \\
\hline $10 / 21 / 04$ & 542 (99) & 408 & 909 & heat & IHPAC \\
\hline $10 / 22 / 04$ & $546(75)$ & 432 & 698 & heat & IHPAC \\
\hline $10 / 23 / 04$ & $527(66)$ & 429 & 623 & heat & IHPAC \\
\hline $10 / 24 / 04$ & $538(69)$ & 433 & 651 & heat & IHPAC \\
\hline $10 / 25 / 04$ & $545(78)$ & 432 & 708 & heat & IHPAC \\
\hline $10 / 26 / 04$ & $536(69)$ & 430 & 678 & heat & IHPAC \\
\hline $10 / 27 / 04$ & $516(68)$ & 407 & 710 & heat & IHPAC \\
\hline $10 / 28 / 04$ & $510(64)$ & 406 & 617 & heat & IHPAC \\
\hline $10 / 29 / 04$ & $560(94)$ & 416 & 834 & mixed & IHPAC \\
\hline $10 / 30 / 04$ & $500(64)$ & 402 & 600 & heat & IHPAC \\
\hline $10 / 31 / 04$ & $471(77)$ & 386 & 617 & heat & IHPAC \\
\hline $11 / 1 / 04$ & $424(22)$ & 368 & 484 & heat & IHPAC \\
\hline $11 / 2 / 04$ & $454(26)$ & 419 & 524 & mixed & IHPAC \\
\hline $11 / 3 / 04$ & $499(65)$ & 394 & 615 & heat & IHPAC \\
\hline $11 / 4 / 04$ & $476(62)$ & 389 & 599 & heat & IHPAC \\
\hline $11 / 5 / 04$ & $527(73)$ & 418 & 645 & heat & IHPAC \\
\hline $11 / 6 / 04$ & $504(70)$ & 396 & 619 & mixed & IHPAC \\
\hline $11 / 7 / 04$ & $497(66)$ & 395 & 584 & heat & IHPAC \\
\hline
\end{tabular}


Table 5. Measured indoor and outdoor carbon dioxide $\left(\mathrm{CO}_{2}\right)$ concentrations and outside air ventilation supply rates in the LBNL RC Test Bed. Ventilation rates were calculated from indoor-minus outdoor steady-state $\mathrm{CO}_{2}$ concentrations. The indoor $\mathrm{CO}_{2}$ source injection rate was approximately $2450 \mathrm{~mL} \mathrm{~min}^{-1}$. Note that on 10/19 and 11/17-18 the outside air damper was closed for part of the day.

\begin{tabular}{|c|c|c|c|c|c|c|c|c|c|c|c|c|c|}
\hline \multirow{2}{*}{$\begin{array}{l}\text { Test } \\
\text { Date }\end{array}$} & \multicolumn{3}{|c|}{ Outside } & \multicolumn{3}{|c|}{ Supply } & \multicolumn{3}{|c|}{ Return } & \multicolumn{2}{|c|}{ OA Flow } & \multirow{2}{*}{$\begin{array}{l}\text { HVAC } \\
\text { Mode }\end{array}$} & \multirow{2}{*}{$\begin{array}{c}\text { HVAC } \\
\text { Type }\end{array}$} \\
\hline & Avg (Stdev) & Min & Max & Avg (Stdev) & Min & Max & Avg (Stdev) & Min & Max & $m^{3} h^{-1}$ & CFM & & \\
\hline $9 / 15 / 04$ & $406(20)$ & 372 & 455 & $464(35)$ & 394 & 525 & $521(58)$ & 394 & 629 & 881 & 519 & cool & 10 SEER \\
\hline $10 / 16 / 04$ & $378(7)$ & 364 & 408 & $463(63)$ & 370 & 539 & $418(31)$ & 364 & 459 & 968 & 570 & heat & IHPAC \\
\hline $10 / 17 / 04$ & $377(8)$ & 364 & 392 & $461(63)$ & 370 & 539 & $417(32)$ & 364 & 459 & 1006 & 592 & None & IHPAC \\
\hline $10 / 18 / 04$ & 383 (12) & 364 & 408 & $477(65)$ & 377 & 572 & $429(34)$ & 370 & 477 & 937 & 552 & heat & IHPAC \\
\hline $10 / 19 / 04$ & $411(25)$ & 377 & 469 & $1040(457)$ & 385 & 1924 & $1016(485)$ & 385 & 1977 & NA & NA & heat & IHPAC \\
\hline $10 / 20 / 04$ & $391(8)$ & 377 & 408 & $477(60)$ & 377 & 560 & $432(32)$ & 377 & 477 & 924 & 544 & heat & IHPAC \\
\hline $10 / 21 / 04$ & 407 (19) & 377 & 459 & $511(103)$ & 377 & 853 & 481 (114) & 377 & 950 & 550 & 324 & heat & IHPAC \\
\hline $10 / 22 / 04$ & $394(8)$ & 377 & 416 & $487(68)$ & 377 & 583 & $438(36)$ & 377 & 497 & 826 & 486 & heat & IHPAC \\
\hline $10 / 23 / 04$ & $387(5)$ & 377 & 399 & $469(60)$ & 377 & 550 & $427(32)$ & 377 & 477 & 941 & 554 & heat & IHPAC \\
\hline $10 / 24 / 04$ & $398(8)$ & 377 & 416 & $483(62)$ & 385 & 560 & $438(34)$ & 385 & 487 & 976 & 575 & heat & IHPAC \\
\hline $10 / 25 / 04$ & $390(7)$ & 377 & 399 & 494 (73) & 385 & 695 & $440(38)$ & 377 & 517 & 633 & 373 & heat & IHPAC \\
\hline $10 / 26 / 04$ & $387(9)$ & 370 & 408 & $480(62)$ & 385 & 572 & $432(33)$ & 385 & 497 & 830 & 488 & heat & IHPAC \\
\hline $10 / 27 / 04$ & $386(6)$ & 377 & 399 & 485 (67) & 377 & 657 & 433 (33) & 385 & 517 & 579 & 341 & heat & IHPAC \\
\hline $10 / 28 / 04$ & $394(8)$ & 375 & 413 & 494 (63) & 390 & 581 & 447 (34) & 390 & 495 & 851 & 501 & heat & IHPAC \\
\hline $10 / 30 / 04$ & $403(9)$ & 383 & 422 & 492 (64) & 390 & 569 & 444 (33) & 390 & 495 & 990 & 583 & heat & IHPAC \\
\hline $10 / 31 / 04$ & 389 (13) & 375 & 430 & 454 (79) & 375 & 581 & $423(46)$ & 375 & 505 & 882 & 519 & heat & IHPAC \\
\hline $11 / 1 / 04$ & 388 (11) & 375 & 413 & 410 (18) & 383 & 448 & 401 (13) & 375 & 430 & NA & NA & heat & IHPAC \\
\hline $11 / 2 / 04$ & $420(17)$ & 397 & 457 & 437 (29) & 405 & 629 & 429 (18) & 405 & 475 & NA & NA & mixed & IHPAC \\
\hline $11 / 3 / 04$ & $387(4)$ & 375 & 397 & $486(64)$ & 383 & 581 & $440(34)$ & 383 & 515 & 818 & 481 & heat & IHPAC \\
\hline $11 / 4 / 04$ & $390(6)$ & 375 & 397 & $473(67)$ & 383 & 581 & $433(34)$ & 383 & 495 & 947 & 558 & heat & IHPAC \\
\hline $11 / 5 / 04$ & 414 (17) & 390 & 466 & $517(73)$ & 405 & 655 & 469 (44) & 405 & 536 & 862 & 507 & heat & IHPAC \\
\hline $11 / 6 / 04$ & 403 (12) & 383 & 422 & $491(69)$ & 390 & 581 & 448 (39) & 383 & 505 & 816 & 480 & mixed & IHPAC \\
\hline $11 / 7 / 04$ & $399(8)$ & 383 & 413 & $485(65)$ & 390 & 569 & $442(36)$ & 383 & 495 & 871 & 513 & heat & IHPAC \\
\hline $11 / 8 / 04$ & 399 (12) & 383 & 430 & $494(66)$ & 390 & 593 & $446(36)$ & 397 & 515 & 892 & 525 & heat & IHPAC \\
\hline $11 / 9 / 04$ & $388(7)$ & 375 & 397 & $476(64)$ & 383 & 558 & 430 (33) & 383 & 475 & 917 & 540 & heat & IHPAC \\
\hline $11 / 10 / 04$ & $391(5)$ & 375 & 405 & $497(73)$ & 390 & 629 & $441(35)$ & 390 & 495 & 705 & 415 & heat & IHPAC \\
\hline $11 / 11 / 04$ & $389(5)$ & 375 & 397 & $510(71)$ & 383 & 604 & $452(38)$ & 383 & 547 & 659 & 388 & heat & IHPAC \\
\hline $11 / 12 / 04$ & $398(10)$ & 383 & 422 & $510(80)$ & 397 & 655 & $452(41)$ & 390 & 525 & 842 & 496 & heat & IHPAC \\
\hline $11 / 13 / 04$ & 397 (10) & 383 & 413 & $484(66)$ & 390 & 581 & $441(34)$ & 390 & 495 & 938 & 552 & heat & IHPAC \\
\hline $11 / 14 / 04$ & 404 (17) & 383 & 438 & $494(76)$ & 390 & 593 & $450(45)$ & 383 & 525 & 903 & 531 & heat & IHPAC \\
\hline $11 / 15 / 04$ & $422(15)$ & 390 & 448 & $526(78)$ & 397 & 629 & $476(41)$ & 397 & 536 & 700 & 412 & heat & IHPAC \\
\hline $11 / 16 / 04$ & $443(30)$ & 390 & 485 & $548(96)$ & 397 & 666 & $499(62)$ & 390 & 581 & 662 & 390 & heat & IHPAC \\
\hline $11 / 17 / 04$ & 430 (49) & 375 & 547 & $607(226)$ & 390 & 1206 & $563(212)$ & 383 & 1091 & NA & NA & heat & IHPAC \\
\hline $11 / 18 / 04$ & $465(51)$ & 390 & 569 & $656(223)$ & 438 & 1186 & $602(200)$ & 422 & 1073 & 561 & 330 & heat & IHPAC \\
\hline
\end{tabular}


Classroom HVAC: Improving and Saving Energy (IVSE) Laboratory Study

Table 7. Measured indoor and outdoor sulfur hexafluoride $\left(\mathrm{SF}_{6}\right)$ tracer gas concentrations and $\mathrm{SF}_{6}$-determined outside air ventilation supply rates in the LBNL RC Test Bed. Ventilation rates were calculated from indoor-minus outdoor steady-state $\mathrm{SF}_{6}$ concentrations. The indoor $\mathrm{SF}_{6}$ source injection rate was approximately $12.5 \mathrm{~mL} \mathrm{~min}{ }^{-1}$.

\begin{tabular}{|c|c|c|c|c|c|c|c|c|c|c|c|c|c|}
\hline \multirow{2}{*}{$\begin{array}{l}\text { Test } \\
\text { Date }\end{array}$} & \multicolumn{3}{|c|}{ Outside $\mathrm{SF}_{6}(\mathrm{ppb})$} & \multicolumn{3}{|c|}{ Supply $\mathrm{SF}_{6}(\mathrm{ppb})$} & \multicolumn{3}{|c|}{ Return $\mathrm{SF}_{6}(\mathrm{ppb})$} & \multicolumn{2}{|c|}{ OA Flow } & \multirow{2}{*}{$\begin{array}{l}\text { HVAC } \\
\text { Mode }\end{array}$} & \multirow{2}{*}{$\begin{array}{c}\text { HVAC } \\
\text { Type }\end{array}$} \\
\hline & Avg (Stdev) & Min & Max & Avg (Stdev) & Min & Max & Avg (Stdev) & Min & Max & $\mathrm{m}^{3} \mathrm{~h}^{-1}$ & CFM & & \\
\hline $9 / 16 / 05$ & $140(9)$ & 13 & 59 & $740(169)$ & 194 & 825 & $504(130)$ & 124 & 589 & 826 & 486 & cool & 10 SEER \\
\hline $10 / 16 / 04$ & $90(53)$ & 21 & 297 & $743(433)$ & 21 & 1801 & $670(396)$ & 21 & 1188 & 896 & 528 & heat & IHPAC \\
\hline $10 / 18 / 04$ & $70(36)$ & 11 & 190 & $648(377)$ & 11 & 1468 & $578(344)$ & 9 & 993 & 1003 & 590 & heat & IHPAC \\
\hline $10 / 19 / 04$ & 248 (144) & 12 & 482 & 3360 (1914) & 16 & 8589 & $2441(1728)$ & 15 & 5719 & 837 & 493 & heat & IHPAC \\
\hline $10 / 20 / 04$ & $82(44)$ & 17 & 247 & $728(423)$ & 17 & 1675 & $653(396)$ & 15 & 1179 & 680 & 400 & heat & IHPAC \\
\hline $10 / 22 / 04$ & $76(52)$ & -1 & 273 & 996 (1180) & 0 & 10123 & $772(366)$ & -2 & 1170 & 822 & 484 & heat & IHPAC \\
\hline $10 / 23 / 04$ & $63(36)$ & 1 & 125 & $720(415)$ & 1 & 1320 & $682(440)$ & -1 & 1528 & 839 & 493 & heat & IHPAC \\
\hline $10 / 24 / 04$ & $60(35)$ & -5 & 125 & $720(414)$ & -5 & 1394 & $661(430)$ & -8 & 1454 & 849 & 499 & heat & IHPAC \\
\hline $10 / 25 / 04$ & $70(44)$ & -5 & 348 & 809 (368) & -3 & 1386 & 773 (379) & -7 & 1432 & 880 & 518 & heat & IHPAC \\
\hline $10 / 26 / 04$ & $60(33)$ & -3 & 121 & $665(396)$ & -5 & 1256 & $663(418)$ & -7 & 1575 & 872 & 513 & heat & IHPAC \\
\hline $10 / 27 / 04$ & $58(34)$ & -2 & 128 & $698(386)$ & -2 & 1292 & $653(407)$ & -4 & 1550 & 859 & 505 & heat & IHPAC \\
\hline $10 / 28 / 04$ & $59(43)$ & -8 & 370 & $687(423)$ & -9 & 1290 & $691(437)$ & -11 & 1618 & 821 & 483 & heat & IHPAC \\
\hline $11 / 2 / 04$ & $938(301)$ & 142 & 1646 & $123(191)$ & 54 & 973 & $984(180)$ & 429 & 1250 & 805 & 474 & mixed & IHPAC \\
\hline $11 / 4 / 04$ & $608(416)$ & -23 & 1702 & $35(37)$ & -23 & 107 & 863 (1232) & -20 & 8009 & 901 & 530 & heat & IHPAC \\
\hline $11 / 5 / 04$ & $655(452)$ & -23 & 2662 & $35(38)$ & -23 & 112 & 934 (1413) & -20 & 9620 & 878 & 517 & heat & IHPAC \\
\hline $11 / 6 / 04$ & $669(421)$ & -23 & 1126 & $40(48)$ & -21 & 277 & 838 (1078) & -18 & 9487 & 816 & 480 & mixed & IHPAC \\
\hline $11 / 7 / 04$ & $658(418)$ & -30 & 1131 & 37 (49) & -29 & 234 & 822 (926) & -28 & 8348 & 818 & 482 & heat & IHPAC \\
\hline $11 / 8 / 04$ & $685(423)$ & -35 & 1190 & $35(56)$ & -34 & 303 & $697(468)$ & -30 & 1511 & 838 & 493 & heat & IHPAC \\
\hline $11 / 9 / 04$ & $661(423)$ & -35 & 1160 & $37(52)$ & -35 & 231 & $703(475)$ & -32 & 1669 & 831 & 489 & heat & IHPAC \\
\hline $11 / 10 / 04$ & $662(420)$ & -35 & 1154 & $36(61)$ & -36 & 293 & $686(465)$ & -33 & 1604 & 837 & 493 & heat & IHPAC \\
\hline $11 / 11 / 04$ & $673(432)$ & -39 & 1184 & $34(65)$ & -41 & 329 & 709 (473) & -37 & 1604 & 839 & 494 & heat & IHPAC \\
\hline
\end{tabular}


Table 8. Performance of the heat pump system (PHPS) by date, on test dates shown. PHPS is the ratio of total enthalpy change of airstreams to energy consumed by the HVAC systems. Data are shown for heating, cooling, and mixed conditioning days for both 10 SEER and IHPAC systems for both school hours and 24 hour periods.

\begin{tabular}{|lccll|}
\hline Study Date & $\begin{array}{c}\text { PHPS } \\
\text { (school) }\end{array}$ & $\begin{array}{c}\text { PHPS } \\
(24 h)\end{array}$ & HVAC & Mode \\
\hline $09 / 14 / 2004$ & 3.55 & 2.61 & 10 SEER Cool \\
$09 / 15 / 2004$ & 2.83 & 2.51 & 10 SEER Cool \\
$09 / 27 / 2004$ & 4.76 & 7.01 & IHPAC & mixed \\
$09 / 28 / 2004$ & 1.94 & 4.65 & IHPAC & mixed \\
$09 / 29 / 2004$ & 7.30 & 4.81 & IHPAC & mixed \\
$09 / 30 / 2004$ & 5.95 & 6.83 & IHPAC & heat \\
$10 / 02 / 2004$ & 3.68 & 4.92 & IHPAC & mixed \\
$10 / 03 / 2004$ & 3.88 & 5.34 & IHPAC & heat \\
$10 / 04 / 2004$ & 2.59 & 3.75 & IHPAC & heat \\
$10 / 05 / 2004$ & 4.01 & 5.48 & IHPAC & heat \\
$10 / 06 / 2004$ & 5.36 & 5.68 & IHPAC & mixed \\
$10 / 07 / 2004$ & 4.25 & 4.61 & IHPAC & cool \\
$10 / 08 / 2004$ & 5.26 & 6.64 & IHPAC & mixed \\
$10 / 09 / 2004$ & 4.41 & 5.97 & IHPAC & mixed \\
$10 / 10 / 2004$ & 4.86 & 7.20 & IHPAC & mixed \\
$10 / 11 / 2004$ & 5.10 & 5.92 & IHPAC & cool \\
$10 / 12 / 2004$ & 4.32 & 3.90 & IHPAC & cool \\
$10 / 13 / 2004$ & 4.11 & 4.11 & IHPAC & cool \\
$10 / 14 / 2004$ & 3.92 & 3.88 & IHPAC & cool \\
$10 / 15 / 2004$ & 3.60 & 4.59 & IHPAC & mixed \\
$10 / 16 / 2004$ & 1.55 & 3.09 & IHPAC & heat \\
$10 / 17 / 2004$ & 1.29 & 1.56 & IHPAC & none \\
$10 / 18 / 2004$ & 3.32 & 4.79 & IHPAC & heat \\
$10 / 19 / 2004$ & 6.80 & 7.77 & IHPAC & heat \\
$10 / 20 / 2004$ & 4.35 & 6.92 & IHPAC & heat \\
$10 / 21 / 2004$ & 4.60 & 8.86 & IHPAC & heat \\
$10 / 22 / 2004$ & 3.60 & 7.40 & IHPAC & heat \\
$10 / 23 / 2004$ & 5.97 & 7.70 & IHPAC & heat \\
\hline
\end{tabular}

\begin{tabular}{|lccll|}
\hline Study Date & PHPS & PHPS & HVAC & Mode \\
& (school) & $(24 h)$ & & \\
\hline $10 / 24 / 2004$ & 3.40 & 7.79 & IHPAC & heat \\
$10 / 25 / 2004$ & 3.97 & 7.12 & IHPAC & heat \\
$10 / 26 / 2004$ & 4.93 & 7.73 IHPAC & heat \\
$10 / 27 / 2004$ & 5.27 & 8.11 & IHPAC & heat \\
$10 / 28 / 2004$ & 4.61 & 7.81 & IHPAC & heat \\
$10 / 29 / 2004$ & 4.00 & 8.54 & IHPAC & mixed \\
$10 / 30 / 2004$ & 4.81 & 7.51 & IHPAC & heat \\
$10 / 31 / 2004$ & 6.39 & 9.38 & IHPAC & heat \\
$11 / 01 / 2004$ & 5.41 & 9.42 & IHPAC & heat \\
$11 / 02 / 2004$ & 4.10 & 8.55 & IHPAC & mixed \\
$11 / 03 / 2004$ & 6.91 & 8.27 & IHPAC & heat \\
$11 / 04 / 2004$ & 5.35 & 6.40 & IHPAC & heat \\
$11 / 05 / 2004$ & 5.29 & 6.82 & IHPAC & heat \\
$11 / 06 / 2004$ & 4.44 & 5.58 & IHPAC & mixed \\
$11 / 07 / 2004$ & 4.80 & 6.08 & IHPAC & heat \\
$11 / 08 / 2004$ & 5.99 & 7.07 & IHPAC & heat \\
$11 / 09 / 2004$ & 6.73 & 7.57 & IHPAC & heat \\
$11 / 10 / 2004$ & 7.80 & 7.38 & IHPAC & heat \\
$11 / 11 / 2004$ & 9.21 & 8.41 & IHPAC & heat \\
$11 / 12 / 2004$ & 6.39 & 6.67 & IHPAC & heat \\
$11 / 19 / 2004$ & 5.09 & 5.76 & IHPAC & heat \\
$11 / 22 / 2004$ & 5.36 & 6.88 & IHPAC & heat \\
$11 / 23 / 2004$ & 4.81 & 5.66 & IHPAC & heat \\
$11 / 24 / 2004$ & 4.37 & 5.09 & IHPAC & heat \\
$03 / 01 / 2005$ & 2.69 & 3.64 & 10 SEER heat \\
$03 / 02 / 2005$ & 2.81 & 3.47 & 10 SEER heat \\
$03 / 03 / 2005$ & 2.98 & 3.67 & 10 SEER heat \\
$03 / 04 / 2005$ & 3.80 & 3.71 & 10 SEER heat \\
$03 / 05 / 2005$ & 3.49 & 3.56 & 10 SEER heat \\
$03 / 06 / 2005$ & 3.59 & 3.42 & 10 SEER heat \\
$03 / 07 / 2005$ & 3.00 & 3.14 & 10 SEER heat \\
$03 / 08 / 2005$ & 3.62 & 3.37 & 10 SEER heat \\
$03 / 09 / 2005$ & 2.78 & 2.84 & 10 SEER mixed \\
$03 / 10 / 2005$ & 2.25 & 2.30 & 10 SEER cool \\
$03 / 11 / 2005$ & 1.88 & 1.87 & 10 SEER cool \\
$03 / 12 / 2005$ & 2.17 & 2.15 & 10 SEER cool \\
$03 / 13 / 2005$ & 1.95 & 2.08 & 10 SEER cool \\
\hline
\end{tabular}

Table 9. Average and standard deviation of PHPS by HVAC type and by conditioning mode.

\begin{tabular}{|c|c|}
\hline HVAC & Avg (Stdev) \\
\hline 10 SEER cool & $2.44(0.64)$ \\
\hline 10 SEER heat & $3.25(0.24)$ \\
\hline 10 SEER mixed & $2.78(----)$ \\
\hline IHPAC cool only & $4.34(0.45)$ \\
\hline IHPAC heat & $5.17(1.4)$ \\
\hline IHPAC mixed (mostly heat) & $4.31(1.5)$ \\
\hline 10SEER all & $2.89(0.63)$ \\
\hline IHPAC all & $4.88(1.4)$ \\
\hline \multicolumn{2}{|l|}{ Ratios } \\
\hline \multicolumn{2}{|c|}{ School Day } \\
\hline 10 SEER/IHPAC (cool) & 0.56 \\
\hline 10 SEER/IHPAC (heat) & 0.63 \\
\hline 10 SEER/IHPAC (all meas.) & 0.59 \\
\hline \multicolumn{2}{|l|}{ 24-hours } \\
\hline 10 SEER/IHPAC (cool) & 0.52 \\
\hline 10 SEER/IHPAC (heat) & 0.50 \\
\hline 10 SEER/IHPAC (all meas.) & 0.46 \\
\hline
\end{tabular}


Table 10. Least Square regression fits between HVAC heating and cooling and HVAC Energy Consumption for both the 10 SEER and IHPAC and for aggregated heating and cooling data and separate space conditioning conditions. Statistics are presented for both school day and daily 24-hour data. PHPS ratios are also included for comparison purposes

\begin{tabular}{|c|c|c|c|c|c|}
\hline $\begin{array}{l}\text { HVAC } \\
\text { System }\end{array}$ & $\begin{array}{l}\text { Conditioning } \\
\text { Mode }\end{array}$ & $\begin{array}{c}\text { Slope } \\
(\mathrm{kW} / \mathrm{kW})\end{array}$ & $\begin{array}{l}\text { Fit } \\
\left(\mathrm{R}^{2}\right)\end{array}$ & $\begin{array}{l}\text { Regression } \\
\text { Ratio }\end{array}$ & $\begin{array}{l}\text { PHPS } \\
\text { Ratio }\end{array}$ \\
\hline \multicolumn{6}{|c|}{ School-Day Data } \\
\hline \multirow[t]{3}{*}{10 SEER } & cool & 2.64 & 0.83 & & \\
\hline & heat & 3.23 & 0.57 & & \\
\hline & All & 3.03 & 0.81 & & \\
\hline \multirow[t]{3}{*}{ IHPAC } & cool & 4.30 & 0.90 & & \\
\hline & heat & 5.10 & 0.61 & & \\
\hline & All Meas. & 4.77 & 0.67 & & \\
\hline \multirow[t]{4}{*}{ Ratio } & cool & & & 0.61 & 0.56 \\
\hline & heat & & & 0.63 & 0.63 \\
\hline & All Meas. & & & 0.63 & 0.59 \\
\hline & Daily & 4 hour Date & & & \\
\hline \multirow[t]{3}{*}{10 SEER } & heat & 3.50 & 0.93 & & \\
\hline & cool & 2.50 & 0.99 & & \\
\hline & All Meas. & 3.43 & 0.97 & & \\
\hline \multirow[t]{3}{*}{ IHPAC } & cool & 4.32 & 0.47 & & \\
\hline & heat & 7.42 & 0.90 & & \\
\hline & All Meas. & 7.04 & 0.83 & & \\
\hline \multirow[t]{3}{*}{ Ratio } & cool & & & 0.58 & 0.52 \\
\hline & heat & & & 0.47 & 0.50 \\
\hline & All Meas. & & & 0.49 & 0.46 \\
\hline
\end{tabular}


Table 11. Acoustic measurements in unoccupied LBNL RC Test Bed. Data include sound levels from the IHPAC, and a 10 SEER HVAC system under three different acoustic installation conditions. Measurements were made at four locations and with fan only, and compressor on. The IHPAC was operated in both Stage 1 and Stage 2 compressor modes. The 10 SEER compressor data are compared with both stages of the IHPAC system. These measurements were made with the RC lighting turned off. Background sound levels in the RC during these measurements, with all equipment off averaged $28 \pm 3.2 \mathrm{~dB}(\mathrm{~A})$, meeting an NC-25 level.

\begin{tabular}{|c|c|c|c|c|c|c|c|c|c|c|c|}
\hline \multirow{2}{*}{\begin{tabular}{|c|} 
Meas. \\
Position \\
Dist. x Ht. \\
$\mathrm{x} \angle$ \\
\end{tabular}} & \multirow[t]{2}{*}{$\begin{array}{c}\text { HVAC } \\
\text { System/Configuration } \\
\end{array}$} & \multicolumn{8}{|c|}{ Sound Pressure dB(linear) } & \multicolumn{2}{|c|}{ Sound Rating } \\
\hline & & $\begin{array}{l}63 \\
\mathrm{~Hz} \\
\end{array}$ & $\begin{array}{l}125 \\
\mathrm{~Hz} \\
\end{array}$ & $\begin{array}{c}250 \\
\mathrm{~Hz} \\
\end{array}$ & $\begin{array}{c}500 \\
\mathrm{~Hz} \\
\end{array}$ & $\begin{array}{c}1000 \\
\mathrm{~Hz}\end{array}$ & $\begin{array}{c}2000 \\
\mathrm{~Hz}\end{array}$ & $\begin{array}{c}4000 \\
\mathrm{~Hz}\end{array}$ & $\begin{array}{c}8000 \\
\mathrm{~Hz}\end{array}$ & $\begin{array}{c}\mathrm{NC} \\
\text { Value }\end{array}$ & $\mathrm{dB}(\mathrm{A})$ \\
\hline \multirow{2}{*}{ FAN } & IHPAC & 44.2 & 39.1 & 26.6 & 26.0 & 21.4 & 16.8 & 17.0 & 19.1 & $\mathrm{NC}-25$ & 34.3 \\
\hline & 10 SEER & 49.2 & 50.9 & 48.4 & 43.6 & 44.4 & 41.2 & 36.9 & 29.4 & NC-45 & 53.5 \\
\hline \multirow[t]{2}{*}{$10 \times 5$} & 10 SEER Sound Wall & 50.7 & 45.6 & 40.5 & 31.6 & 30.5 & 18.2 & 14.4 & 13.0 & NC-30 & 41.2 \\
\hline & 10 SEER Sound Curb & 47.9 & 43.3 & 36.7 & 32.4 & 26.4 & 19.3 & 16.3 & 20.1 & NC-30 & 41.5 \\
\hline \multirow{2}{*}{ FAN } & 10 SEER & 45.9 & 38.9 & 24.5 & 22.6 & 15.8 & 13.4 & 9.4 & 20.1 & $\mathrm{NC}-25$ & 32.8 \\
\hline & 10 SEER & 50.6 & 49.4 & 43.4 & 39.5 & 39.4 & 35.1 & 31.4 & 26.0 & NC-40 & 48.8 \\
\hline \multirow[t]{2}{*}{$10 \times 5 \times 45^{\circ}$} & 10 SEER Sound Wall & 46.2 & 50.2 & 41.0 & 32.2 & 31.1 & 18.9 & 14.8 & 12.9 & $\mathrm{NC}-35$ & 42.5 \\
\hline & 10 SEER Sound Curb & 44.3 & 45.4 & 36.4 & 28.7 & 25.8 & 21.4 & 18.3 & 12.1 & $\mathrm{NC}-30$ & 41.2 \\
\hline \multirow{2}{*}{ FAN } & IHPAC & 43.8 & 35.1 & 26.8 & 21.2 & 21.3 & 16.9 & 15.0 & 20.1 & $\mathrm{NC}-25$ & 32.0 \\
\hline & 10 SEER & 47.0 & 44.4 & 40.2 & 37.9 & 36.1 & 33.7 & 29.1 & 24.4 & $\mathrm{NC}-40$ & 47.0 \\
\hline \multirow[t]{2}{*}{$20 \times 5$} & 10 SEER Sound Wall & 50.0 & 45.6 & 37.8 & 29.6 & 32.3 & 16.7 & 11.7 & 20.1 & $\mathrm{NC}-35$ & 39.9 \\
\hline & 10 SEER Sound Curb & 43.2 & 41.0 & 37.7 & 31.4 & 26.8 & 19.4 & 13.6 & 20.1 & $\mathrm{NC}-30$ & 38.7 \\
\hline \multirow{2}{*}{ FAN } & IHPAC & 38.5 & 32.8 & 23.0 & 19.3 & 19.7 & 13.3 & 11.1 & 20.1 & $\mathrm{NC}-25$ & 29.2 \\
\hline & 10 SEER & 45.2 & 40.5 & 38.6 & 37.0 & 34.1 & 30.9 & 26.1 & 23.2 & $\mathrm{NC}-35$ & 44.8 \\
\hline \multirow[t]{2}{*}{$30 \times 5$} & 10 SEER Sound Wall & 51.0 & 46.9 & 32.9 & 29.0 & 33.8 & 16.5 & 10.4 & 20.1 & NC-35 & 40.5 \\
\hline & 10 SEER Sound Curb & 45.1 & 39.9 & 34.4 & 29.0 & 23.1 & 15.6 & 11.1 & 20.1 & $\mathrm{NC}-25$ & 36.9 \\
\hline \multirow{2}{*}{ STAGE1 } & IHPAC & 61.0 & 48.5 & 34.1 & 33.1 & 21.5 & 16.5 & 14.3 & 13.9 & NC-40 & 40.8 \\
\hline & 10 SEER & 66.8 & 55.5 & 57.5 & 44.6 & 43.3 & 39.9 & 36.8 & 31.5 & NC-50 & 55.2 \\
\hline \multirow[t]{2}{*}{$10 \times 5$} & 10 SEER Sound Wall & 72.3 & 48.9 & 50.0 & 34.5 & 26.5 & 23.0 & 20.6 & 17.3 & NC-55 & 49.1 \\
\hline & 10 SEER Sound Curb & 66.7 & 50.6 & 39.4 & 35.2 & 32.9 & 25.7 & 23.8 & 19.9 & $\mathrm{NC}-45$ & 47.3 \\
\hline \multirow{2}{*}{ STAGE1 } & IHPAC & 55.5 & 51.5 & 31.5 & 33.0 & 19.1 & 13.3 & 10.8 & 20.1 & $\mathrm{NC}-35$ & 39.9 \\
\hline & 10 SEER & 71.4 & 58.5 & 53.9 & 42.8 & 40.2 & 36.7 & 33.1 & 28.1 & NC-55 & 54.4 \\
\hline \multirow[t]{2}{*}{$10 \times 5 \times 45^{\circ}$} & 10 SEER Sound Wall & 62.2 & 51.2 & 43.6 & 35.3 & 28.7 & 21.7 & 18.6 & 16.3 & NC-40 & 45.2 \\
\hline & 10 SEER Sound Curb & 59.2 & 49.5 & 40.0 & 33.7 & 29.7 & 23.0 & 20.0 & 16.9 & $\mathrm{NC}-35$ & 45.1 \\
\hline \multirow{2}{*}{ STAGE1 } & IHPAC & 54.3 & 43.3 & 30.7 & 26.1 & 18.0 & 12.0 & 18.0 & 20.1 & NC-30 & 36.1 \\
\hline & 10 SEER & 61.9 & 54.4 & 47.9 & 41.0 & 37.2 & 34.1 & 31.6 & 26.3 & $\mathrm{NC}-40$ & 50.5 \\
\hline \multirow[t]{2}{*}{$20 \times 5$} & 10 SEER Sound Wall & 70.1 & 52.0 & 45.6 & 32.2 & 25.5 & 17.0 & 14.3 & 12.3 & NC-50 & 46.4 \\
\hline & 10 SEER Sound Curb & 63.5 & 42.9 & 37.5 & 33.3 & 29.6 & 21.1 & 19.6 & 16.2 & NC-40 & 41.9 \\
\hline ST $\triangle G F 1$ & IHPAC & 49.9 & 45.5 & 29.5 & 28.1 & 14.8 & 10.2 & 18.0 & 20.1 & NC-30 & 34.6 \\
\hline S1AGEl & 10 SEER & 60.9 & 48.3 & 44.7 & 40.1 & 35.0 & 32.3 & 29.0 & 24.7 & NC-40 & 47.8 \\
\hline $30 \times 5$ & 10 SEER Sound Wall & 61.8 & 49.0 & 38.2 & 31.9 & 24.1 & 15.0 & 12.8 & 20.1 & NC-40 & 41.9 \\
\hline & 10 SEER Sound Curb & 65.8 & 43.3 & 33.8 & 32.6 & 26.0 & 18.9 & 16.6 & 13.9 & $\mathrm{NC}-45$ & 42.5 \\
\hline & IHPAC & 60.8 & 52.1 & 36.3 & 33.0 & 30.1 & 24.2 & 16.6 & 12.1 & NC-40 & 42.7 \\
\hline STAGE2 & 10 SEER & 66.8 & 55.5 & 57.5 & 44.6 & 43.3 & 39.9 & 36.8 & 31.5 & NC-50 & 55.2 \\
\hline $10 \times 5$ & 10 SEER Sound Wall & 72.3 & 48.9 & 50.0 & 34.5 & 26.5 & 23.0 & 20.6 & 17.3 & NC-55 & 49.1 \\
\hline & 10 SEER Sound Curb & 66.7 & 50.6 & 39.4 & 35.2 & 32.9 & 25.7 & 23.8 & 19.9 & $\mathrm{NC}-45$ & 47.3 \\
\hline & IHPAC & 57.5 & 49.8 & 33.8 & 32.6 & 24.7 & 21.7 & 15.7 & 11.9 & $\mathrm{NC}-35$ & 40.6 \\
\hline STAC & 10 SEER & 71.4 & 58.5 & 53.9 & 42.8 & 40.2 & 36.7 & 33.1 & 28.1 & NC-55 & 54.4 \\
\hline $10 \times 5 \times 45^{\circ}$ & 10 SEER Sound Wall & 62.2 & 51.2 & 43.6 & 35.3 & 28.7 & 21.7 & 18.6 & 16.3 & NC-40 & 45.2 \\
\hline & 10 SEER Sound Curb & 59.2 & 49.5 & 40.0 & 33.7 & 29.7 & 23.0 & 20.0 & 16.9 & $\mathrm{NC}-35$ & 45.1 \\
\hline & IHPAC & 54.5 & 47.4 & 35.4 & 27.2 & 25.7 & 20.3 & 13.0 & 20.1 & NC-30 & 38.8 \\
\hline STAGE2 & 10 SEER & 61.9 & 54.4 & 47.9 & 41.0 & 37.2 & 34.1 & 31.6 & 26.3 & $\mathrm{NC}-40$ & 50.5 \\
\hline $20 \times 5$ & 10 SEER Sound Wall & 70.1 & 52.0 & 45.6 & 32.2 & 25.5 & 17.0 & 14.3 & 12.3 & NC-50 & 46.4 \\
\hline & 10 SEER Sound Curb & 63.5 & 42.9 & 37.5 & 33.3 & 29.6 & 21.1 & 19.6 & 16.2 & NC-40 & 41.9 \\
\hline & IHPAC & 50.0 & 43.0 & 31.1 & 28.7 & 21.0 & 19.0 & 14.0 & 20.1 & $\mathrm{NC}-25$ & 35.9 \\
\hline S IAGE2 & 10 SEER & 60.9 & 48.3 & 44.7 & 40.1 & 35.0 & 32.3 & 29.0 & 24.7 & NC-40 & 47.8 \\
\hline $30 \times 5$ & 10 SEER Sound Wall & 61.8 & 49.0 & 38.2 & 31.9 & 24.1 & 15.0 & 12.8 & 20.1 & NC-40 & 41.9 \\
\hline & 10 SEER Sound Curb & 65.8 & 43.3 & 33.8 & 32.6 & 26.0 & 18.9 & 16.6 & 13.9 & $\mathrm{NC}-45$ & 42.5 \\
\hline
\end{tabular}




\section{Figures}

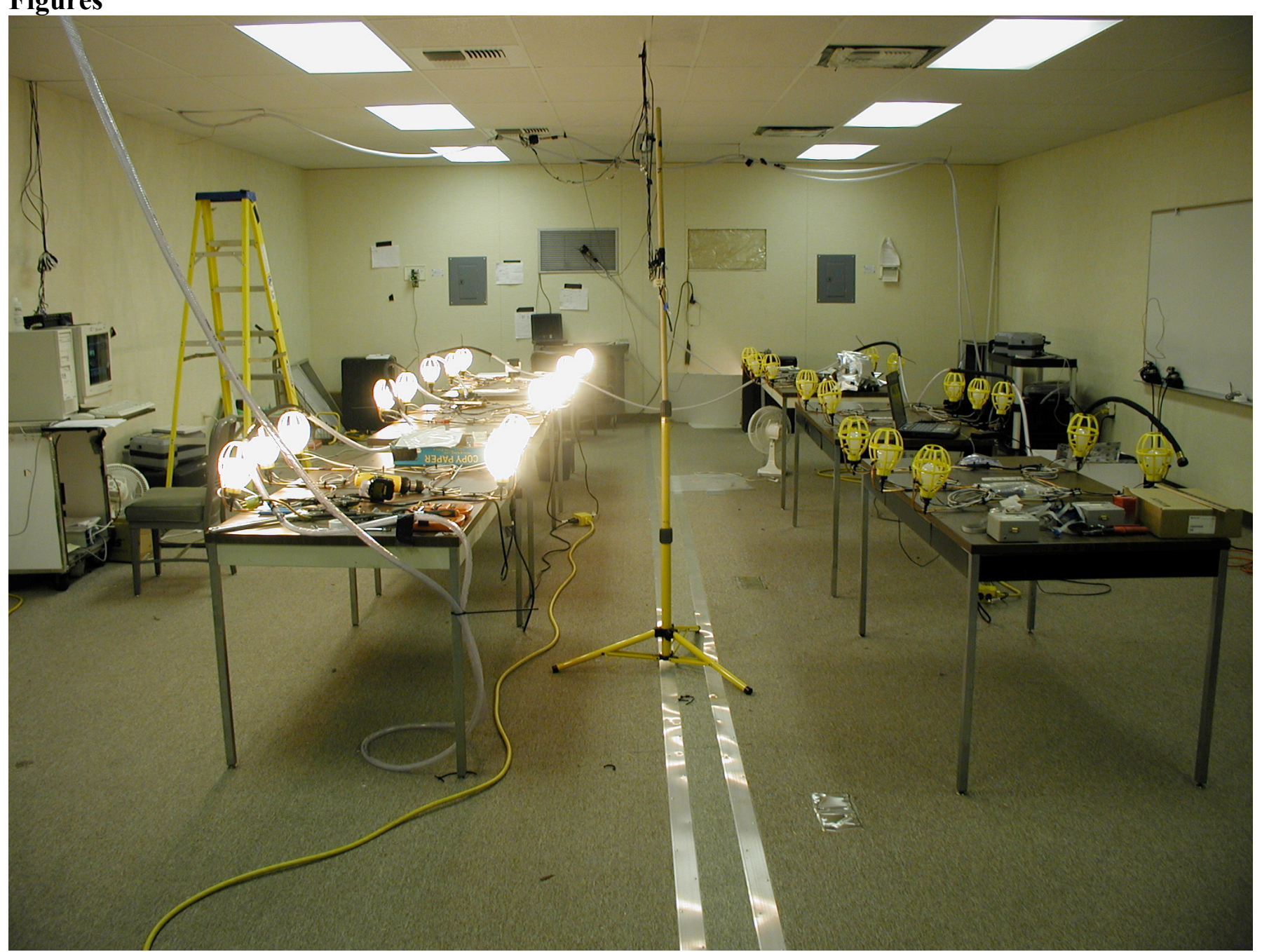

Figure 1. Photograph of interior of LBNL RC Test Bed depicting the occupant simulation system including $60 \mathrm{~W}$ light bulbs (50\% on in this case). Also note dual HVAC systems. The system on the left is the IHPAC and on the right is the 10SEER unit (sealed during IHPAC operation). The room monitoring sensors are located on the stand in the center. Duct and return sensor cables may be seen on the IHPAC side as well. Data from these sensors are logged using the APT datalogger seen on the left above the computer stand. 


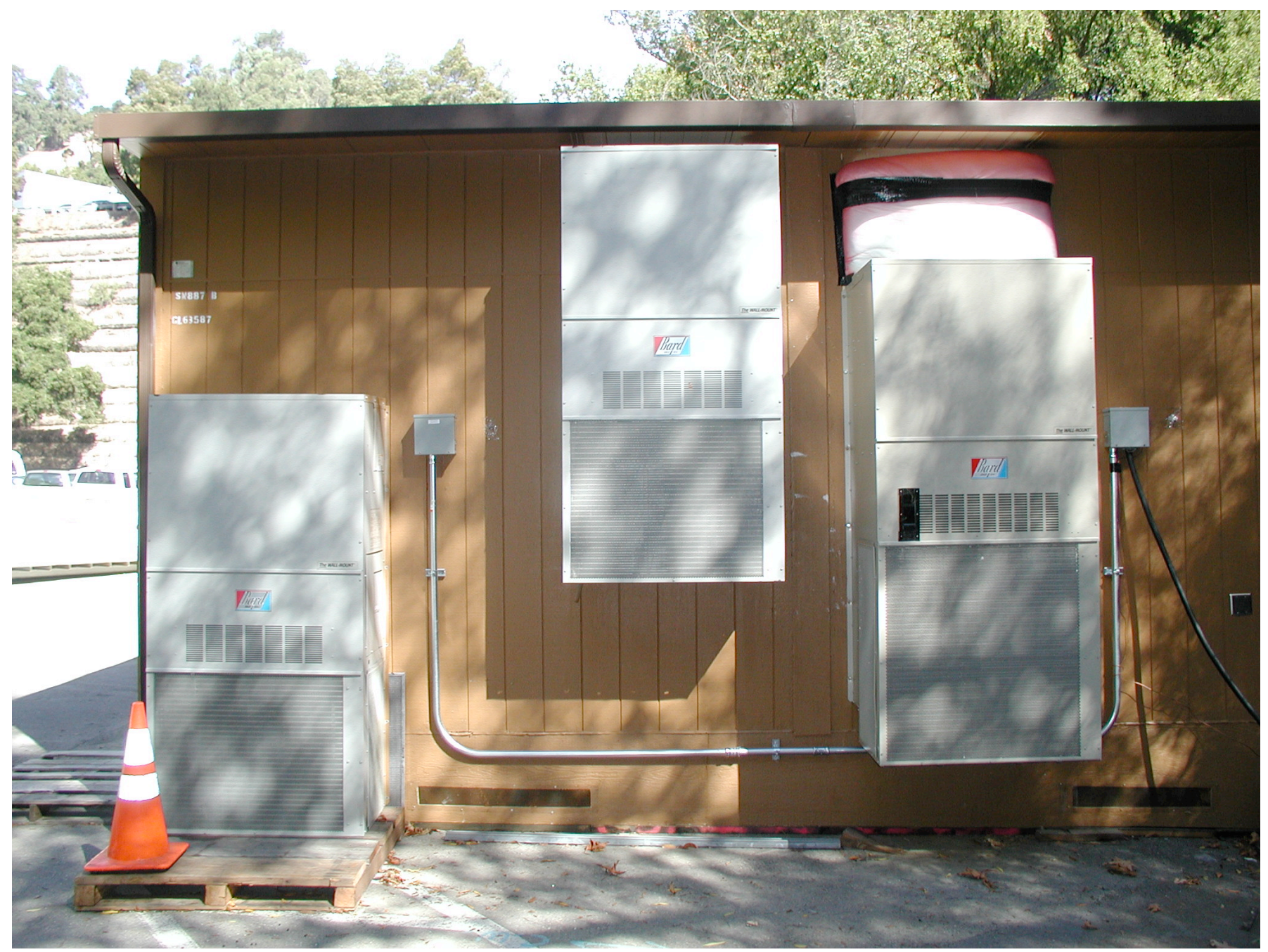

Figure 2. External wall of LBNL RC Test Bed showing the 10 SEER (left) and prototype IHPAC (right) wall-mount units. Batt insulation seen above the IHPAC was used prior to completion of an insulated top discharge duct. The third HVAC system on the far left was the original system on this RC. 


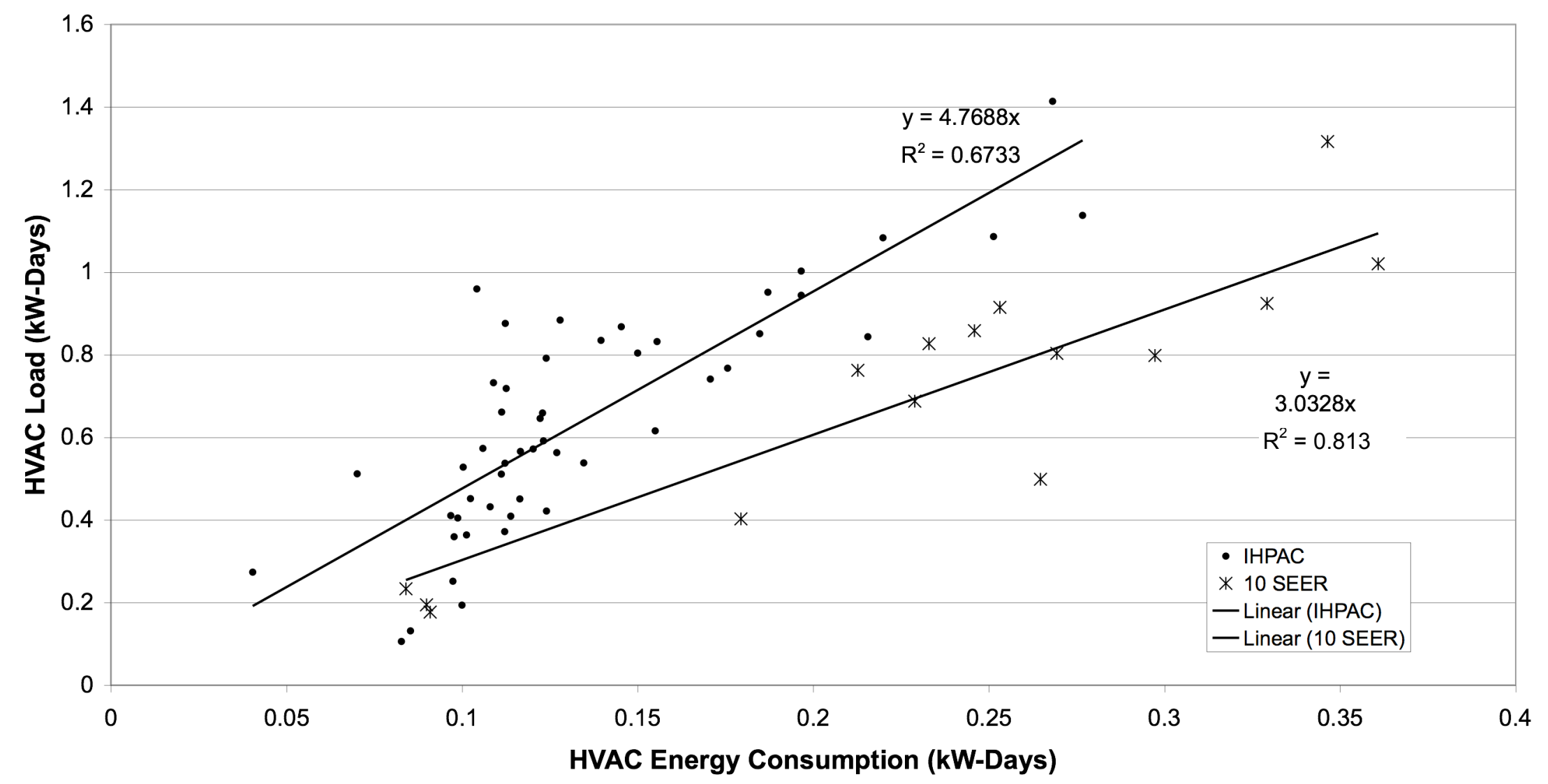

Figure 3. HVAC heating and cooling versus HVAC Energy Consumption in both heating and cooling modes during school day periods (08:00 to 14:30 Monday - Friday). 


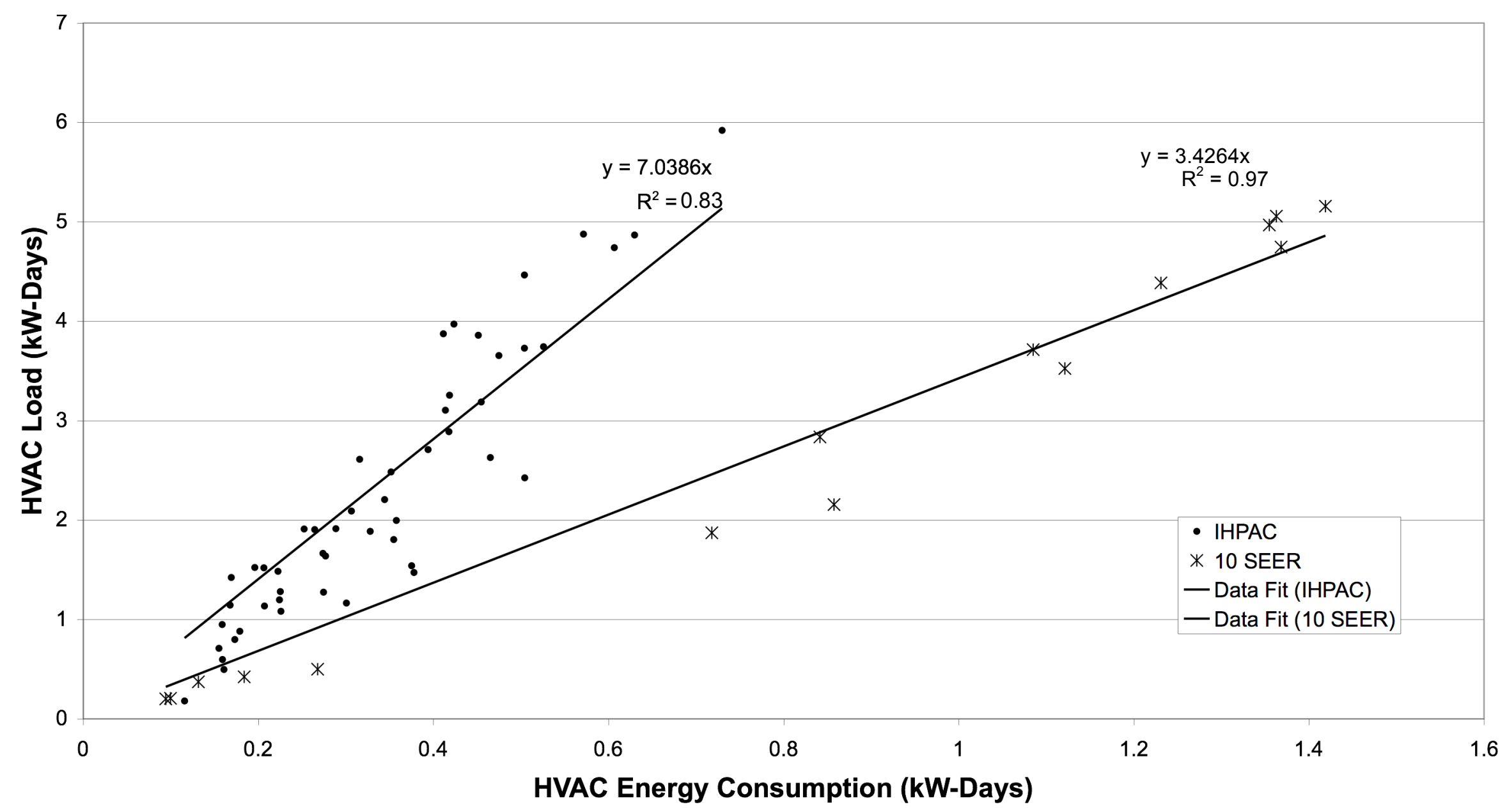

Figure 4. HVAC heating and cooling versus HVAC Energy Consumption in both heating and cooling modes during daily 24 hour periods). 